\title{
Impact of air-sea coupling on the climate change signal over the Iberian Peninsula
}

\author{
Alba de la Vara ${ }^{1,2} \cdot$ William Cabos $^{3} \cdot$ Dmitry V. Sein $^{4,5} \cdot$ Claas Teichmann $^{6} \cdot$ Daniela Jacob $^{6}$
}

Received: 23 July 2020 / Accepted: 6 May 2021

(c) The Author(s) 2021

\begin{abstract}
In this work we use a regional atmosphere-ocean coupled model (RAOCM) and its stand-alone atmospheric component to gain insight into the impact of atmosphere-ocean coupling on the climate change signal over the Iberian Peninsula (IP). The IP climate is influenced by both the Atlantic Ocean and the Mediterranean sea. Complex interactions with the orography take place there and high-resolution models are required to realistically reproduce its current and future climate. We find that under the RCP8.5 scenario, the generalized 2-m air temperature (T2M) increase by the end of the twenty-first century (2070-2099) in the atmospheric-only simulation is tempered by the coupling. The impact of coupling is specially seen in summer, when the warming is stronger. Precipitation shows regionally-dependent changes in winter, whilst a drier climate is found in summer. The coupling generally reduces the magnitude of the changes. Differences in T2M and precipitation between the coupled and uncoupled simulations are caused by changes in the Atlantic large-scale circulation and in the Mediterranean Sea. Additionally, the differences in projected changes of T2M and precipitation with the RAOCM under the RCP8.5 and RCP4.5 scenarios are tackled. Results show that in winter and summer T2M increases less and precipitation changes are of a smaller magnitude with the RCP4.5. Whilst in summer changes present a similar regional distribution in both runs, in winter there are some differences in the NW of the IP due to differences in the North Atlantic circulation. The differences in the climate change signal from the RAOCM and the driving Global Coupled Model show that regionalization has an effect in terms of higher resolution over the land and ocean.
\end{abstract}

Keywords Iberian Peninsula $\cdot$ Future climate $\cdot$ Climate change $\cdot$ Air-sea coupling $\cdot$ Regional climate modeling

Dmitry V. Sein

dmitry.sein@awi.de

1 Environmental Sciences Institute, University of Castilla-La Mancha, Avenida Carlos III S/N, 45071 Toledo, Spain

2 Departamento de Matemática Aplicada a la Ingeniería Industrial, E.T.S.I. Industriales, Universidad Politécnica de Madrid, C/ José Gutiérrez Abascal, 2, 28006 Madrid, Spain

3 Departmento de Física y Matemáticas, Universidad de Alcalá, Alcalá de Henares, Madrid, Spain

4 P. P. Shirshov Institute of Oceanology RAS, Moscow, Russia

5 Alfred Wegener Institute for Polar and Marine Research, Bremerhaven, Germany

6 Climate Service Center Germany (GERICS), Helmholtz-Zentrum Hereon, 20095 Hamburg, Germany

\section{Introduction}

In the context of a changing climate, knowledge about the possible scenarios of the evolution of the future climate in vulnerable regions is essential to minimize negative socioeconomic impacts. For this purpose, the only tool available to perform the necessary climate projections and study the corresponding causal mechanisms and feedbacks are the Earth System Models (ESMs) (Taylor et al. 2012). As computational power has increased over time, longer climatic simulations with a finer resolution of the model's components are being carried out. However, despite the progress in model design (e.g., Sein et al. 2018) and computing resources, horizontal resolution of current state-of-the-art ESMs (about $50-100 \mathrm{~km}$ in the ocean and $70-200 \mathrm{~km}$ in the atmosphere) used in long term climate simulations is still not fine enough for regional purposes (Collins et al. 2018). Therefore, the only possibility to study regional climates 
with enough horizontal resolution to capture key processes is with Regional Climate Models (RCMs; e.g., Rummukainen 2016).

The major advantage of RCMs is that their enhanced spatial resolution, which can be achieved using smaller domains, allows for a more realistic representation of topography, land-sea gradients and mesoscale processes. In particular, regional atmosphere-ocean coupled models (RAOCMs) are fundamental tools for studying the climate responses to this anthropogenic forcing. They have been successfully applied to study regions where air-sea feedbacks are important to achieve a realistic representation of climate (Di Sante et al. 2019) in different parts of the world, such as the Arctic (e.g., Sein et al. 2014), the North Atlantic (Sein et al. 2015), the Tropical Atlantic (Cabos et al. 2017; Sun et al. 2019), the Indian Ocean (Sein et al. 2020b) or the Mediterranean Sea (Akhtar et al. 2018; Somot et al. 2018; Darmaraki et al. 2019; Parras-Berrocal et al. 2020). In future climate projections, the Mediterranean region has been identified as one of the most relevant climate hotspots (Giorgi 2006). The reason lies in its particular location between central Europe and North Africa. Whilst the first one has a temperate and rainy climate, the second one is very arid. Thus, the Mediterranean region can be regarded as a transitional zone between the two. Due to its location, the Mediterranean Sea is very sensitive to changes in the general circulation (e.g., Lionello et al. 2006; Ulbrich et al. 2006). Even small changes can have a large impact on regional climate and thus the climate change signal is amplified.

In the Mediterranean region, the climate of the Iberian Peninsula (IP) stands out because it witnesses a marked spatial and seasonal variability. The observed climate variability in the IP is the result of the interaction of different air masses with an abrupt topography, in combination with the existing land-sea contrasts. In particular, in winter, the climate of the IP is affected by changes in the large-scale oceanic circulation in the North Atlantic subtropical Gyre. In summer, the influence of the Mediterranean Sea on the climate of the IP becomes more relevant (e.g., Cabos et al. 2020). The IP climate is set by the position of the Azores High and the Icelandic Low (e.g., Martín-Vide and Olcina 2001), as well as by the oceanic circulation in the North Atlantic. Specifically, in winter, the subtropical high-pressure cell is weaker and positioned at lower latitudes. This causes the IP to be affected by westerly circulation and perturbations originated by the polar front. In summer, the Iceland Low pressure system is weaker, the Azores High is reinforced and expands towards higher latitudes, blocking the western circulation over the IP except for the northern region, which is still affected by it. The northerly winds associated with the Azores High trigger upwelling of cold, nutrient-rich intermediate-depth waters and southward surface circulation along the western Iberian coasts (Bakun and Nelson 1991;
Soares et al. 2014; Rijo et al. 2017). Additionally, the climate of the IP is also influenced by the Mediterranean Sea circulation (Martin-Vide and Lopez-Bustins, 2006). In addition to coastal processes, the Mediterranean Sea affects the Iberian climate via air masses that enter the IP from the east or the southeast (Font-Tullot 2000). Therefore, future changes of the North Atlantic ocean surface current system and (or) the Mediterranean Sea water properties could have a significant impact on the future climate of the IP.

The climate of the IP and the Mediterranean Sea have been studied in the framework of the ENSEMBLES (Van der Linden and Mitchell, 2009), Euro-CORDEX and Med-CORDEX (European and Mediterranean Coordinated Regional Climate Downscaling Experiment, respectively) projects for present time and climate projections (e.g., Giorgi et al. 1992, 1997; Rotach et al. 1997; Semmler and Jacob 2004; Déqué et al. 2005; Cardoso et al. 2019; Herrera et al. 2020). However, the regional simulations carried out for these projects do not include explicitly the whole North Atlantic, which plays a relevant role for the European climate and in particular, for the IP. As state-of-the-art ESMs do not explicitly resolve many coupled processes that play a relevant role for the IP climate. As discussed in former works, we need an oceanic eddy-permitting resolution to simulate the most relevant features of the North Atlantic circulation (Marzocchi et al. 2015) and enhanced atmospheric resolution to represent adequately the storm-track response to global warming (Willison et al. 2015) and extratropical cyclone activity, especially to the northeast of the North Atlantic (Michaelis et al. 2017). It was also suggested that changes in the land-sea temperature gradient will induce changes in the along-shore winds in the eastern boundary upwelling systems which could depend on model resolution (de la Vara et al. 2020). In the Mediterranean, it was found that coupling improves the simulated wind speed (particularly near coastal areas) and subsequently the turbulent heat fluxes (Akhtar et al. 2018). Thus, it is desirable to analyze the way the explicit representation of these processes affects the climate change signal in the IP in a high-resolution coupled regional climate model.

Therefore, here we study the role of air-sea coupling on the climate change signal of the IP in climate change simulations with a RAOCM and its atmospheric component, assuming different emission scenarios. In most works in which the climate change signal in Europe (and in the IP) is studied (Van der Linden and Mitchell 2009; Jacob et al. 2014) the Mediterranean Sea is not included in the model domain. Different to those works, our setup allows us to detect the relative contributions of the North Atlantic and the Mediterranean Sea, simultaneously, on the climate change signal of the IP. A special effort is done to understand the driving mechanisms of the changes observed in the climate of the IP. This work is structured as follows. In Sect. 2, the 
model setups and simulations performed are described. In Sect. 3, temperature and precipitation changes for the coupled and uncoupled atmospheric simulations under the RCP8.5 scenario are presented and compared. Then, we study the role of the radiative scenario in the magnitude and spatial patterns of the climate change signal. Also, the added value of finer resolution in the RAOCM with respect to the driving global model is tackled. In Sect. 4, the causes for the differences in the climate change signal between ROM and REMO are addressed. A summary and the conclusions are given in Sect. 5.

\section{Model setup and simulations}

In this work we use the same setup of the regionally-coupled model ROM (REMO-OASIS-MPIOM; Sein et al. 2015) and its stand-alone atmospheric component REMO (REgional MOdel; Jacob and Podzun 1997; Jacob 2001) that are used in Cabos et al. (2020). Both models, REMO (Déqué et al. 2012; Jiménez-Guerrero et al. 2013; Kotlarski et al. 2014) and ROM (Sein et al. 2014; Cabos et al. 2018; Darmaraki et al. 2019) have been extensively adopted to gain insight into regional climate and climate change signal in different regions of the world, including the IP, with a similar performance to the best state-of-the-art models (Cabos et al. 2017; Sein et al. 2020a). Over the peninsula, the magnitude and sign of the 2-m air temperature and precipitation biases obtained depend on the specific model adopted (ROM or REMO) and shows great spatial and seasonal variability. In this respect, ROM air temperature is warmer in winter and colder in summer than in REMO. Precipitation differences between ROM and REMO show great spatial variability and are of a smaller magnitude in summer (see Cabos et al. 2020 for details).

ROM is composed of the Max Planck Institute Ocean Model (MPIOM; Marsland et al. 2003; Jungclaus et al. 2013) and the aforementioned regional atmospheric model REMO. Both models are hydrostatic and solve the Navier-Stokes equations using the Boussinesq approximation. MPIOM has an orthogonal curvilinear grid that allows us to attain a maximum resolution of $5 \mathrm{~km}$ (eddy permitting) near the IP and a minimum resolution of about $100 \mathrm{~km}$ in the southern seas. On the vertical, MPIOM has 47 unevenly spaced $z$-levels the thickness of which increases progressively. The shallowest and deepest levels have a thickness of $16 \mathrm{~m}$ and $650 \mathrm{~m}$, respectively. In MPIOM the water exchange at Gibraltar and the Black Sea is not parameterized. Moreover, Atlantic water properties are not relaxed towards climatological values in the areas adjacent to the strait. The ocean dynamics of the Strait of Gibraltar is fully resolved in MPIOM.

In REMO a rotated grid with the center of the model domain located around the equator is used. In the experiments we perform REMO has a constant horizontal resolution of $0.25^{\circ}$. On the vertical, the model has 27 hybrid levels. The dynamics of REMO is based on the EuropaModel of the German Weather service (Majewski 1991), whilst physical parameterizations derive from versions 4 and 5 of the global climate model ECHAM (European Centre Hamburg Model; Roeckner et al. 1996, 2003). In REMO, most of the prognostic variables are relaxed towards forcing data in the outer eight rows of the model area following Davies (1976). A radiative upper boundary condition is applied following Klemp and Durran (1983) and Bougeault (1983). The atmospheric domain includes the North Atlantic and the Mediterranean Sea simultaneously, which is beneficial for the understanding of the relative contribution of the Mediterranean and the Atlantic on the projected changes. The global Hydrological Discharge model (HD, Hagemann and Dümenil Gates 2001) computes river runoff and is coupled to both the ocean and the atmosphere.

The coupling of REMO and MPIOM is done via the OASIS coupler (Valcke et al. 2003). Atmospheric and oceanic fields are exchanged with a 3-h coupling time step (see Sein et al. 2015). For more details on the ROM setup we refer the reader to Cabos et al. (2020). In previous studies, ROM has shown the ability to provide a climate change signal that reflects not only the higher resolution of its components, but generates a regional signal that is significantly different from the one provided by the driving model (Limareva et al. 2017; Cabos et al. 2018; Sein et al. 2020a). In the experiments analyzed in this work, ROM is forced by climate change simulations with the low-resolution version of the MPI-ESM Earth System Model (Max-Planck-Institut für Meteorologie Earth System Model; Giorgetta et al. 2013) under the Representative Concentration Scenarios RCP8.5 and RCP4.5 Coupled Model Intercomparison Project CMIP5 scenarios, which represent one high-emission and one medium-stabilization scenario. ROM and MPI-ESM share the same oceanic component, but the MPIOM setup used in MPI-ESM is quite different from the setup used in ROM. In MPI-ESM the poles of the orthogonal curvilinear coordinates are located over Greenland and inland of the Weddell Sea, in order to have the higher horizontal resolution in the deep water formation areas, with a minimum grid spacing of about $15 \mathrm{~km}$ around Greenland (Jungclaus et al. 2006). In ROM the poles are placed over North America and Western Africa (see Fig. 1SA of the Supplementary Material), producing a high-resolution region near the IP, which reaches $5 \mathrm{~km}$ in the southern part of the IP. Also, ROM has a good representation of the diurnal cycle ( $3 \mathrm{~h}$ coupled time step), which is neglected in the MPI-ESM simulations.

Before the production runs, MPIOM has been forced with ERA-40 data during three cycles of 44 years (1958-2001), then forced by ERA-Interim during two cycles of 32 years (1980-2012). Each run started from 
the last year of the previous run. Then, the coupled model was run for 32 years forced by ERA-Interim using the last state of the uncoupled MPIOM spin-up. Finally, both the coupled and atmospheric-only model were run for 56 years (1950-2005) starting from the last state of the coupled simulation forced by ERA-Interim. As for the analysis of these present-time simulations, we use the 1976-2005 period, the models have 26 more years for adjustment. The climate change simulations started from the last state of the present-time simulations and covered the 2006-2099 period.

\section{Results}

In this section we analyze the impact of the high resolution and the coupling on the regional climate change signal under the RCP8.5 and RCP4.5 scenarios. For this we use the delta changes of the most important climate variables in the MPI-ESM simulations and their dynamical downscaling with REMO and ROM. We define the delta change of a climate variable as the difference between its future (2070-2099) and present time (1976-2005) seasonal mean. A summary of the average values at the end of the century, as well as the delta changes of these variables, that is, the 2-m air temperature (i.e., T2M, TMIN, TMAX) and precipitation over the IP for REMO and ROM are shown in Table 1.

\subsection{Climate change signal in the Iberian Peninsula in the coupled simulation}

Here we characterize the future values of T2M, TMIN, TMAX and precipitation for the 2070-2099 period and the associated delta changes $(\Delta)$ for the coupled simulation under the RCP8.5 scenario.

\subsubsection{Mean, maximum and minimum 2-m air temperature}

As expected, the simulated $\mathrm{T} 2 \mathrm{M}$ at the end of the century is strongly influenced by the topography (Fig. 1a, b), with lowest values over the highly-elevated mountain chains (e.g., Pyrenees, Cantabrian Mountains, Iberian System, Betic Cordillera; see location in Fig. 1SB). In winter, T2M has an averaged value of $9.21^{\circ} \mathrm{C}$, attaining minimum values as low as $5^{\circ} \mathrm{C}$ over the mountain chains (Fig. 1a). Elsewhere, T2M takes higher values (but not greater than $16^{\circ} \mathrm{C}$ ). In summer, T2M takes an averaged value of $25.45^{\circ} \mathrm{C}$. The highest temperatures are registered in the southern portion of the IP, especially along the Guadalquivir river basin, where values of T2M close to $32{ }^{\circ} \mathrm{C}$ are achieved (Fig. 1b). The lowest summer temperatures are reached along the Pyrenees, with values close to $16^{\circ} \mathrm{C}$.

Focusing on $\Delta \mathrm{T} 2 \mathrm{M}$, we note that it is positive all over the IP (Fig. 1c), with an average value of $2.83^{\circ} \mathrm{C}$ in winter. The effect of topography is visible, as the increases are more pronounced over the mountain chains. A similar general increase of air temperature in mountain chains has been found in previous works (Bartók et al. 2017) and the implied mechanisms such as changes in albedo and in downward thermal radiation are discussed in e.g., Rangwala and Miller (2012) and Palazzi et al. (2019). In summer, changes of T2M are stronger than in winter. T2M increases are lower by the shore, rising more sharply in the interior regions, where delta changes can be greater than $5^{\circ} \mathrm{C}$ (Fig. 1d). The average increase of $\mathrm{T} 2 \mathrm{M}$ in this season is $4.75^{\circ} \mathrm{C}$. The generalized T2M increase, more pronounced in the summer months than in winter, is in line with results from the climate projections from Giorgi and Lionello (2008), although they assume different time periods and scenarios. In a recent paper, Garrido et al. (2020), using an uncoupled regional model and a

Table 1 Summary of winter and summer averages of T2M, TMAX, TMIN $\left({ }^{\circ} \mathrm{C}\right)$ and precipitation (mm/day) over the Iberian Peninsula for the different simulations performed in this study for future climate, as well as the corresponding change with respect to the present-day run

\begin{tabular}{|c|c|c|c|c|c|c|c|c|c|}
\hline & & \multicolumn{2}{|c|}{$\mathrm{T} 2 \mathrm{M}\left({ }^{\circ} \mathrm{C}\right)$} & \multicolumn{2}{|c|}{$\operatorname{TMAX}\left({ }^{\circ} \mathrm{C}\right)$} & \multicolumn{2}{|c|}{ TMIN $\left({ }^{\circ} \mathrm{C}\right)$} & \multicolumn{2}{|c|}{$\begin{array}{l}\text { Precipitation }(\mathrm{mm} / \\
\text { day) }\end{array}$} \\
\hline & & Winter & Summer & Winter & Summer & Winter & Summer & Winter & Summer \\
\hline \multirow[t]{2}{*}{ ROM RCP8.5 } & Future average & 9.21 & 25.45 & 14.19 & 33.31 & 5.70 & 18.52 & 2.71 & 0.33 \\
\hline & Future change & 2.83 & 4.75 & 3.16 & 5.29 & 2.55 & 4.25 & 0.005 & -0.39 \\
\hline \multirow[t]{2}{*}{ REMO RCP8.5 } & Future average & 9.43 & 25.69 & 13.93 & 33.23 & 6.18 & 19.06 & 3.47 & 0.44 \\
\hline & Future change & 2.89 & 5.02 & 3.12 & 5.60 & 2.68 & 4.50 & 0.17 & -0.50 \\
\hline \multirow[t]{2}{*}{ ROM RCP4.5 } & Future average & 7.58 & 23.18 & 12.21 & 30.47 & 4.21 & 16.41 & 2.68 & 0.72 \\
\hline & Future change & 1.21 & 2.47 & 1.39 & 2.84 & 1.05 & 2.14 & -0.02 & -0.29 \\
\hline \multirow[t]{2}{*}{ MPI-ESM RCP8.5 } & Future average & 10.01 & 26.08 & 14.25 & 31.45 & 8.42 & 21.20 & 2.67 & 0.41 \\
\hline & Future change & 2.98 & 5.93 & 3.23 & 6.60 & 2.84 & 5.59 & -0.15 & -0.46 \\
\hline
\end{tabular}



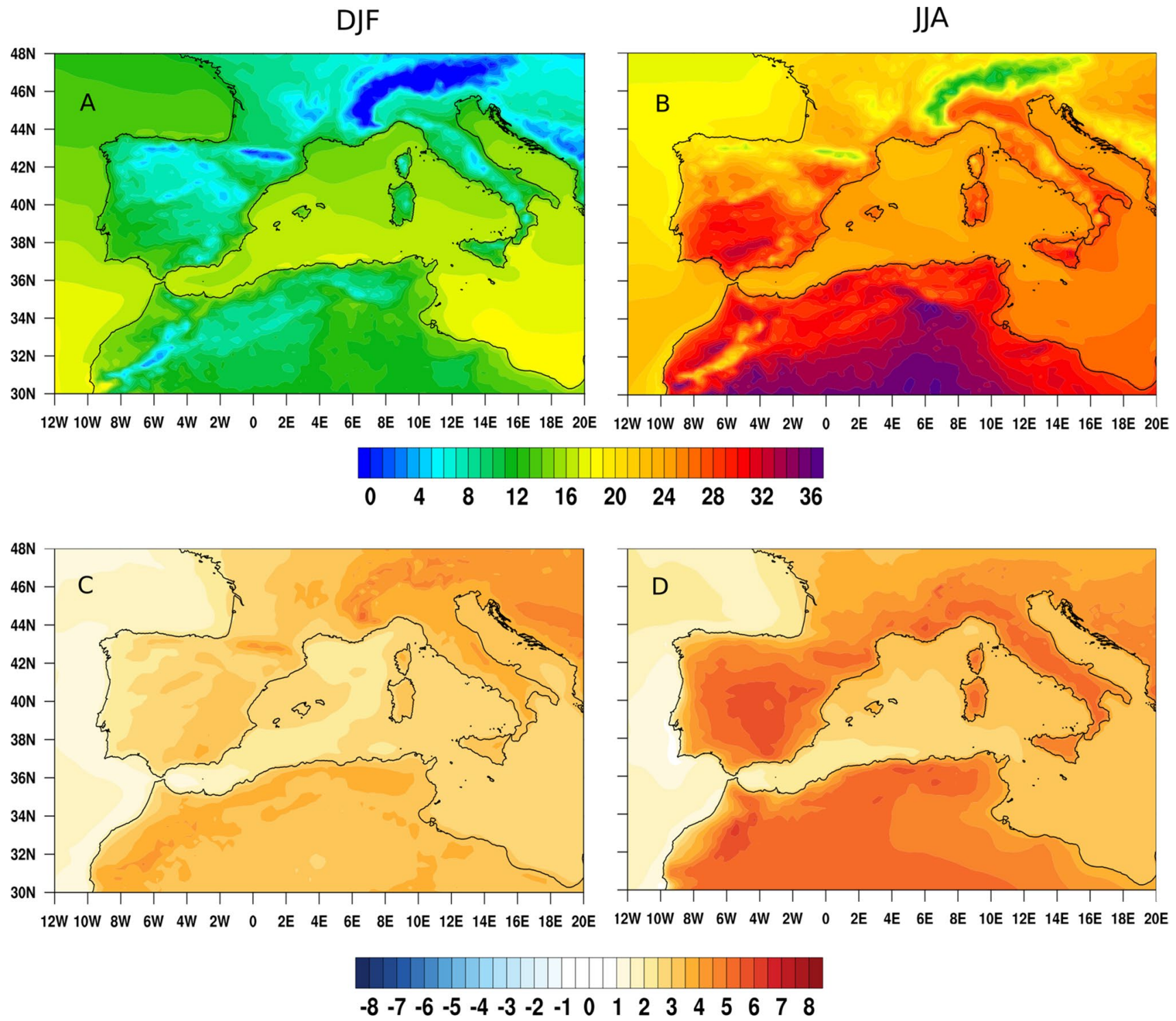

Fig. 1 Panels a and b: Seasonal averages of 2-m air temperature (T2M), in ${ }^{\circ} \mathrm{C}$, computed for the future (RCP8.5 scenario) in ROM. Panels c and d: Seasonal differences of future and present T2M in ROM. Positive values indicate a T2M increase in the future and

different driving global model, have shown results for $\Delta \mathrm{T} 2 \mathrm{M}$ qualitatively similar to ours for the CMIP5 scenarios. Specifically, they find that the delta change for T2M is higher in summer and that there is an east-west gradient in winter and a north-south gradient in summer. Regarding the last season, this north-south asymmetry in our coupled setup is not as clear as in the uncoupled downscaling, suggesting a reduction of the warming by the active ocean. The different spatial patterns of $\Delta \mathrm{T} 2 \mathrm{M}$ in the two seasons point to different physical mechanisms responsible for the warming. The winter change is stronger over the mountains and seems to be related to the large-scale circulation, while in the summer, the changes in insolation seem to prevail and the ocean-land negative values the opposite. Winter plots $(\mathrm{DJF}=$ December, January, February) are depicted in the left column and the summer ones (JJA = June, July; August) in the right column

interaction plays an important role, decreasing the warming onshore.

The regional distribution of TMAX is similar to that for T2M for all seasons, but with higher temperatures and subtle differences in the spatial distribution (Fig. 2a, b). For instance, the winter mean value of TMAX is $14.19^{\circ} \mathrm{C}$, with minimum values over the Pyrenees $\left(\sim 5^{\circ} \mathrm{C}\right)$ and the maximum values in this season, close to $20^{\circ} \mathrm{C}$ appear in the near shore of the southern and eastern coasts of the IP (Fig. 2a). In summer, the average TMAX is $33.31^{\circ} \mathrm{C}$, reaching $\sim 40^{\circ} \mathrm{C}$ in the Guadalquivir basin and minimum values of $\sim 24^{\circ} \mathrm{C}$ in the Pyrenees (Fig. 2b). $\triangle \mathrm{TMAX}$ is stronger than $\triangle \mathrm{T} 2 \mathrm{M}$ in both seasons, with a similar spatial pattern, with an average 
DJF

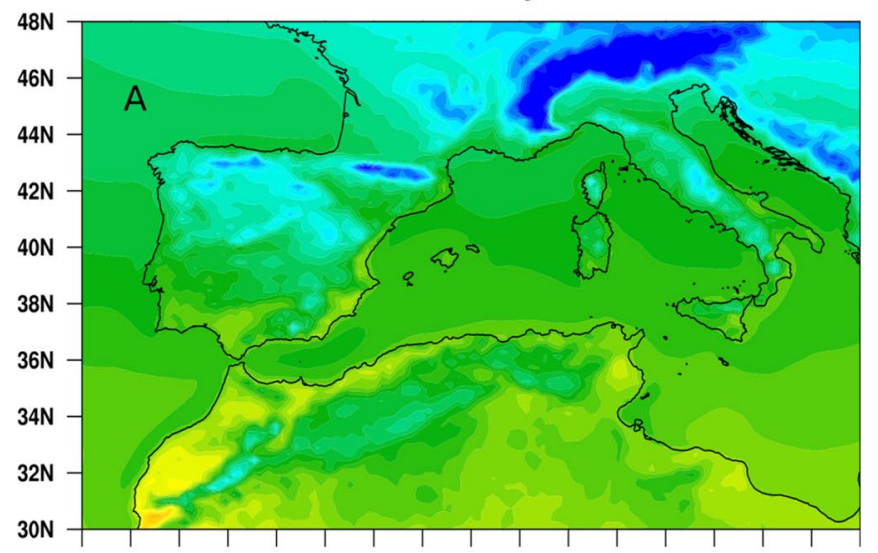

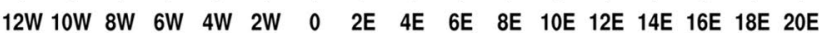

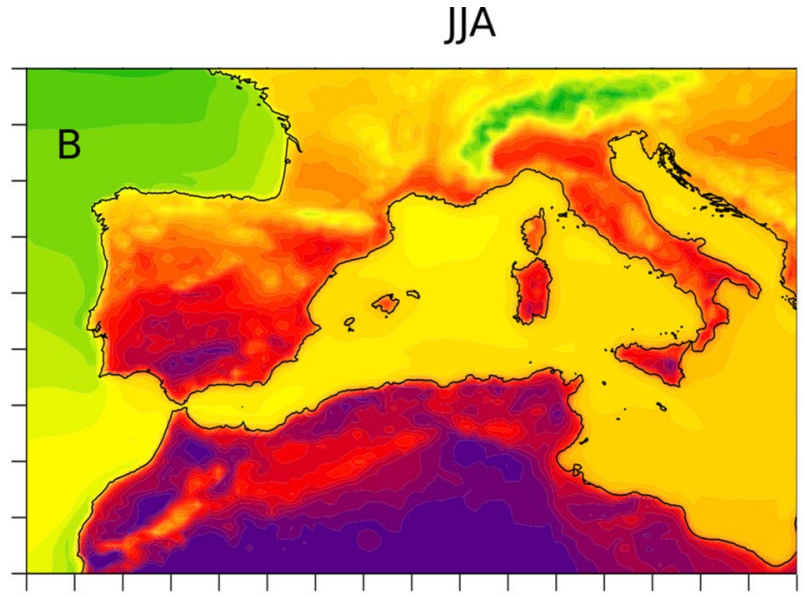

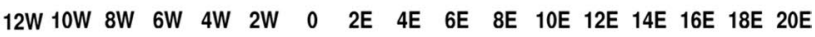
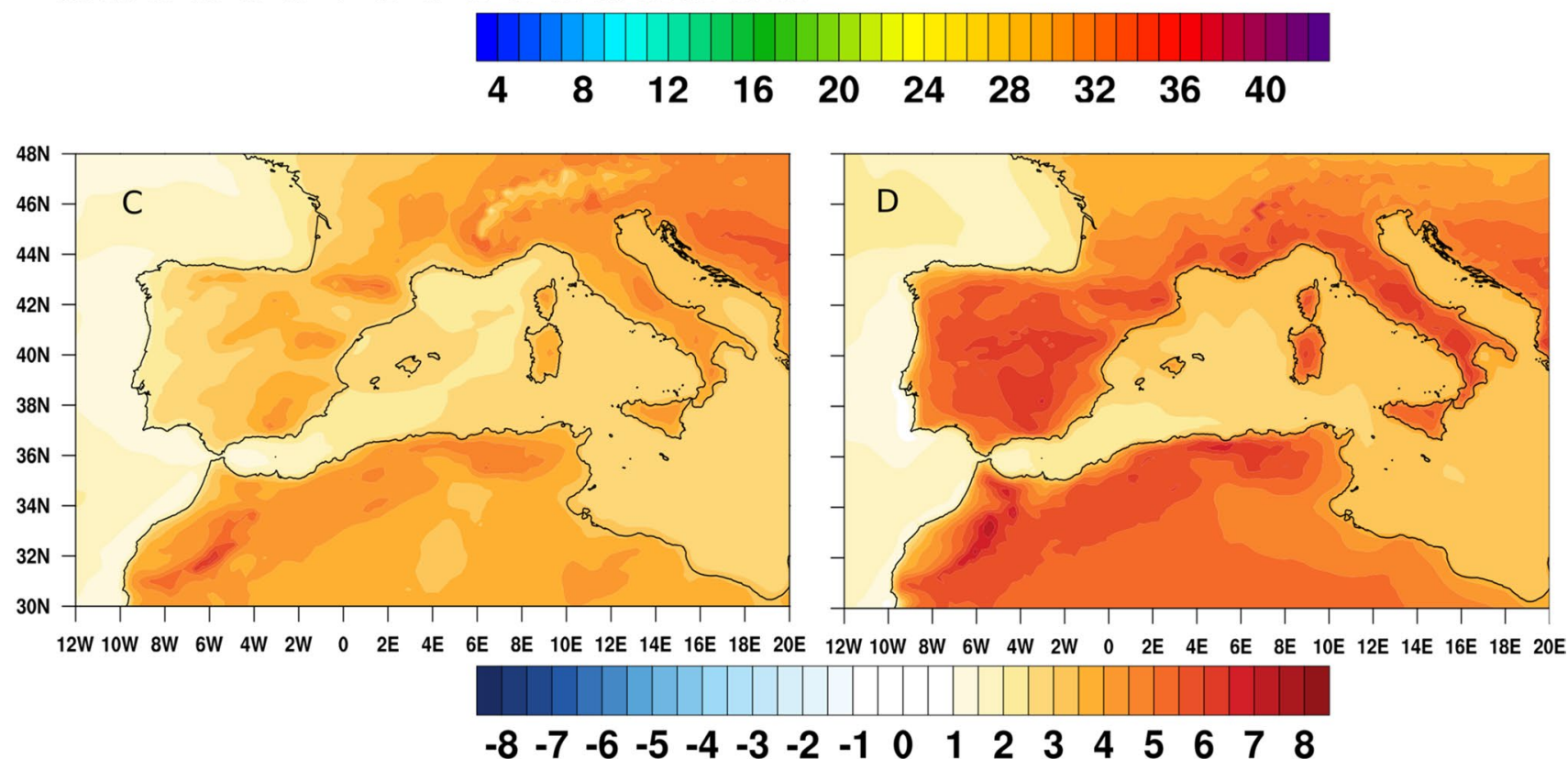

Fig. 2 As for Fig. 1, but for TMAX

value of $3.16^{\circ} \mathrm{C}$ in winter. Again, there is a clear effect of topography in winter, with a more pronounced increase, which can be larger than $4^{\circ} \mathrm{C}$, over the most relevant mountain chains (Fig. 2c). Similarly to $\Delta \mathrm{T} 2 \mathrm{M}$, the increase is higher in the interior regions, independently of the orography. The highest values of $\triangle \operatorname{TMAX}\left(\sim 6.5^{\circ} \mathrm{C}\right)$ are now attained in the interior high plains (Fig. 2d).

In winter, future daily TMIN takes an average value of $5.70{ }^{\circ} \mathrm{C}$ and has a similar spatial distribution than $\mathrm{T} 2 \mathrm{M}$ and TMAX (Fig. 3a, b). The lowest values of TMIN $\left(\sim-4{ }^{\circ} \mathrm{C}\right)$ are reached in high, northern areas and maximum $\left(\sim 12^{\circ} \mathrm{C}\right)$ near the eastern and southern coasts of the IP (Fig. 3a). The average summer TMIN is $18.52{ }^{\circ} \mathrm{C}$ and attains values as low as $10^{\circ} \mathrm{C}$ in the mountains of northern Spain and values above $20^{\circ} \mathrm{C}$ are found in the southern portion of the IP (Fig. 3b). Future changes of TMIN also broadly resemble those for T2M and TMAX (Fig. 3c, d), but with lower values. In winter, $\triangle \mathrm{TMIN}$ has an average value of $2.55^{\circ} \mathrm{C}$. Increases are in the $2-3^{\circ} \mathrm{C}$ range over most of the IP, being stronger over the mountains, especially over the Pyrenees (Fig. 3c). In summer, the spatial distribution of $\Delta$ TMIN (average value of $4.25^{\circ} \mathrm{C}$ ) is more similar to $\Delta \mathrm{T} 2 \mathrm{M}$ than to $\triangle$ TMAX, with higher values $\left(\sim 4-5{ }^{\circ} \mathrm{C}\right)$, in the southern plains of the IP, which become progressively smaller towards the coast (Fig. 3d).

\subsubsection{Precipitation over the Iberian Peninsula}

Future winter precipitation over the IP takes an average value of $2.71 \mathrm{~mm} / \mathrm{d}$ and presents a marked west-to-east gradient with the lowest values to the east (Fig. 4a), in line with present-day precipitation (Rodríguez-Puebla et al. 1998, 

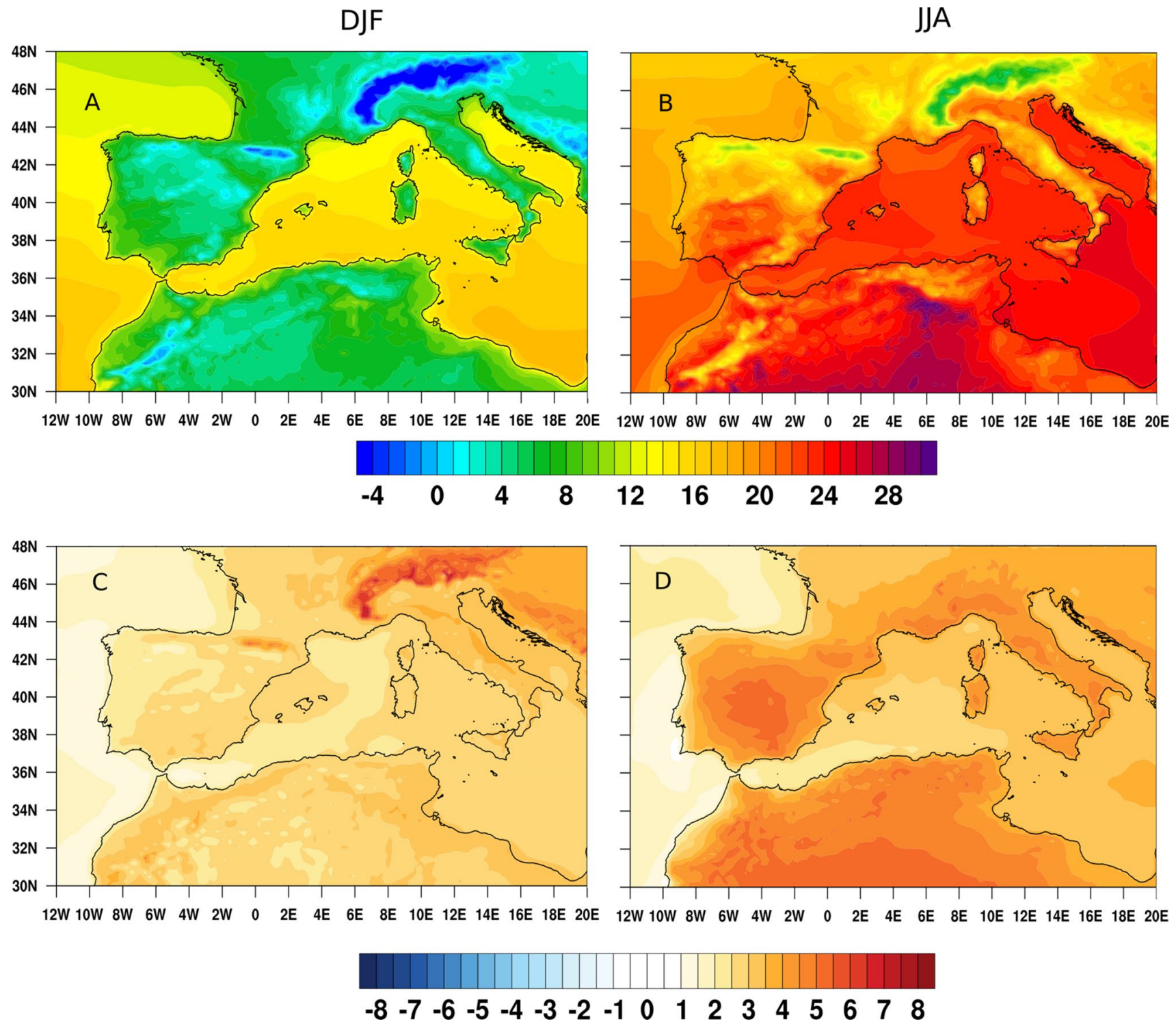

Fig. 3 As for Fig. 1, but for TMIN

2001; Cardoso et al. 2019; Cabos et al. 2020). As today, future precipitation is largest along the northern portion of the IP and, especially, along its NW flank, where it takes values close to $8-10 \mathrm{~mm} /$ day or even higher. This points to the first-order influence exerted by the Atlantic large-scale atmospheric circulation through the arrival of fronts to the IP (e.g., Zorita et al. 1992). To the SE, winter precipitation is close to (or lower than) $1 \mathrm{~mm} /$ day. Values of winter $\Delta$ Prec (delta precipitation; Fig. 4c) are positive along the northwestern rim of the IP where the precipitation increase can reach $2 \mathrm{~mm} /$ day. The region of precipitation increase, which is under the influence of the Atlantic storms, extends to the interior of the IP. In contrast, precipitation substantially drops along the northern margin of the IP up to a maximum of about $1.5 \mathrm{~mm} /$ day. A remarkable precipitation decrease, which is not as large as over the northern part of the IP, is also observed in the southernmost portion of the IP and to the SE, in the Andalusia area, close to the Betic Cordillera. The changes are of opposite sign across the IP and almost balance when the spatial summ is computed, giving a mean increase lower than $0.01 \mathrm{~mm} /$ day $(0.005 \mathrm{~mm} /$ day, equivalent to $0.18 \%$ ), which is not statistically significant.

In the future, as for the present-day (Durán et al. 2013), summer precipitation is much lower than in winter (the mean precipitation within the peninsula is $0.33 \mathrm{~mm} /$ day), with a clear north-south gradient (Fig. 4b). Precipitation is more abundant to the north, although values are relatively low (less than $1 \mathrm{~mm} /$ day). The strongest precipitation is recorded in the Pyrenees, where precipitation can reach about $1.5 \mathrm{~mm} /$ day probably due to the topographic effect 
DJF

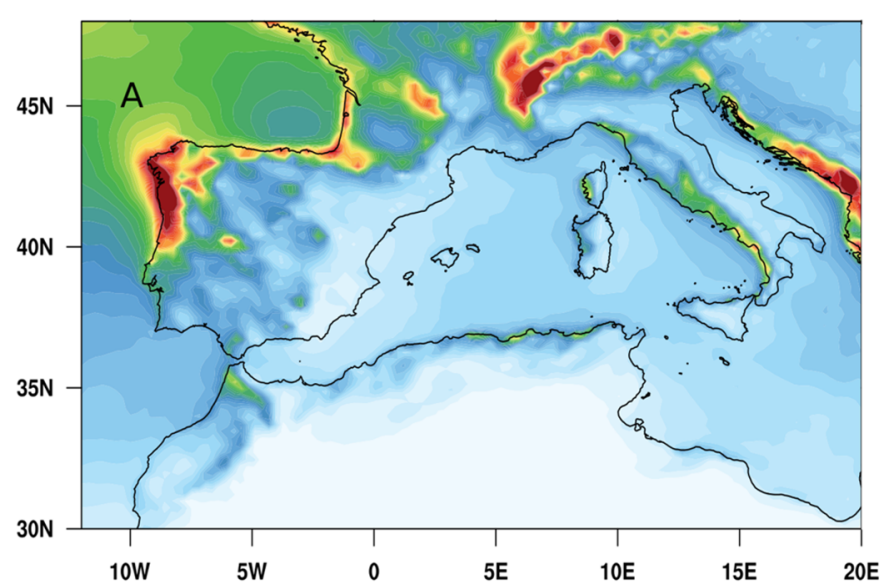

JJA

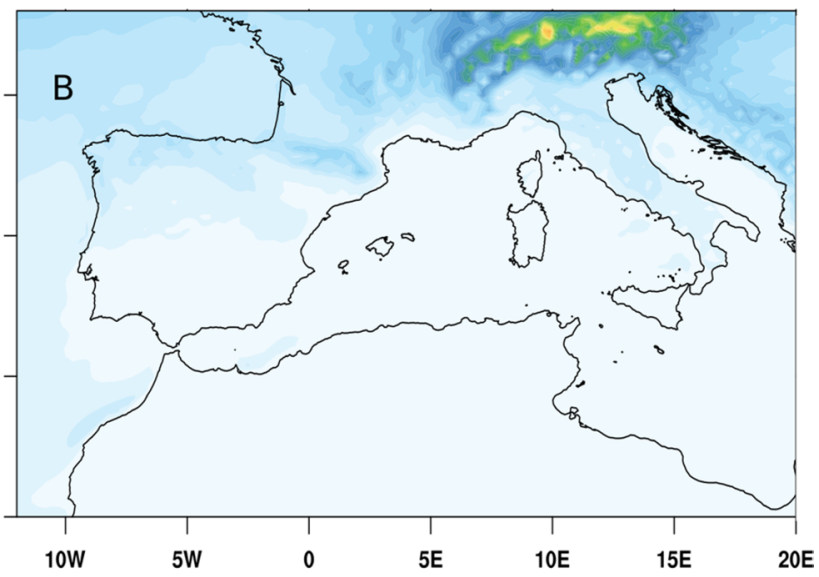

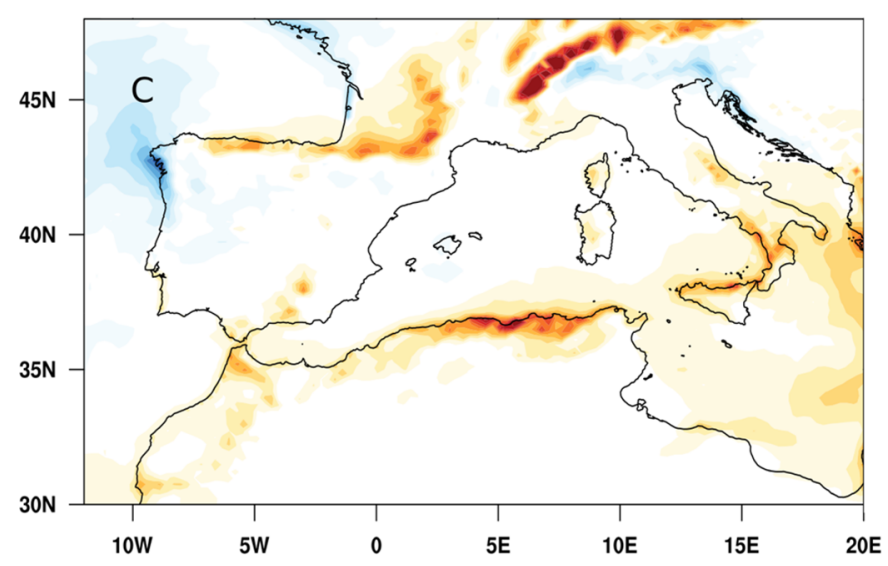
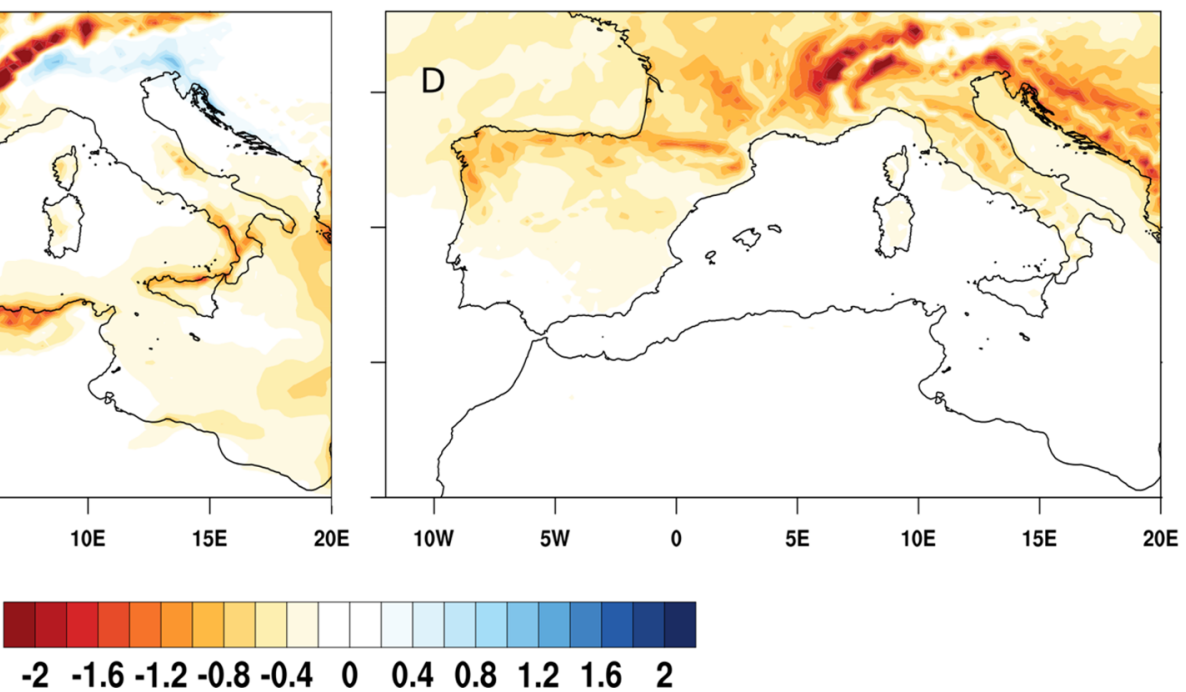

Fig. 4 Panels a and b: Seasonal averages of precipitation, in $\mathrm{mm} /$ day, computed for the future (RCP8.5 scenario) in ROM. Panels $\mathbf{c}$ and $\mathbf{d}$ : Seasonal differences of future and present precipitation in ROM. Pos-

(Torma and Giorgi 2020). In the southern portion of the IP, summer precipitation is scarce. As at present, drier conditions in summer relate to the secondary role of the Atlantic large-scale circulation, being convective processes the main cause for summer rain in the IP (Ramos et al. 2014). Regarding summer $\Delta$ prec, we observe a generalized drop with regionally-variable magnitude and an average value of $0.39 \mathrm{~mm} /$ day (Fig. 4d). The strongest decrease occurs along the northern flank of the IP, where the reduction in precipitation can be larger than $1 \mathrm{~mm} /$ day. Precipitation decreases less to the SW of the IP. This is related to the fact that precipitation is smallest there in the summer season. Comparing itive values correspond to a precipitation increase in the future and negative values the opposite. Winter plots are shown in the left column and the summer ones in the right column

our results to previous works, we find that future precipitation changes are qualitatively in line with those obtained for a global climate model ensemble from Giorgi and Lionello (2008) for the B1 scenario and the work by Gao et al. (2006) for the A2 scenario for the end of the twenty-first century.

\subsection{Impact of air-sea coupling on the climate change signal over the IP}

In order to analyze the impact of air-sea coupling on the climate change signal of the IP, we will compare the delta changes of temperature and precipitation in ROM to the 
delta changes in the stand-alone simulations with REMO. We should stress that the configuration of REMO in the stand alone simulation is the same that in ROM.

\subsubsection{Effect of air-sea interactions on the 2-m air temperature}

Figure 5 shows the difference of winter and summer delta change of 2-m air temperature, between ROM (coupled) and REMO (uncoupled) when the RCP8.5 scenario is assumed,
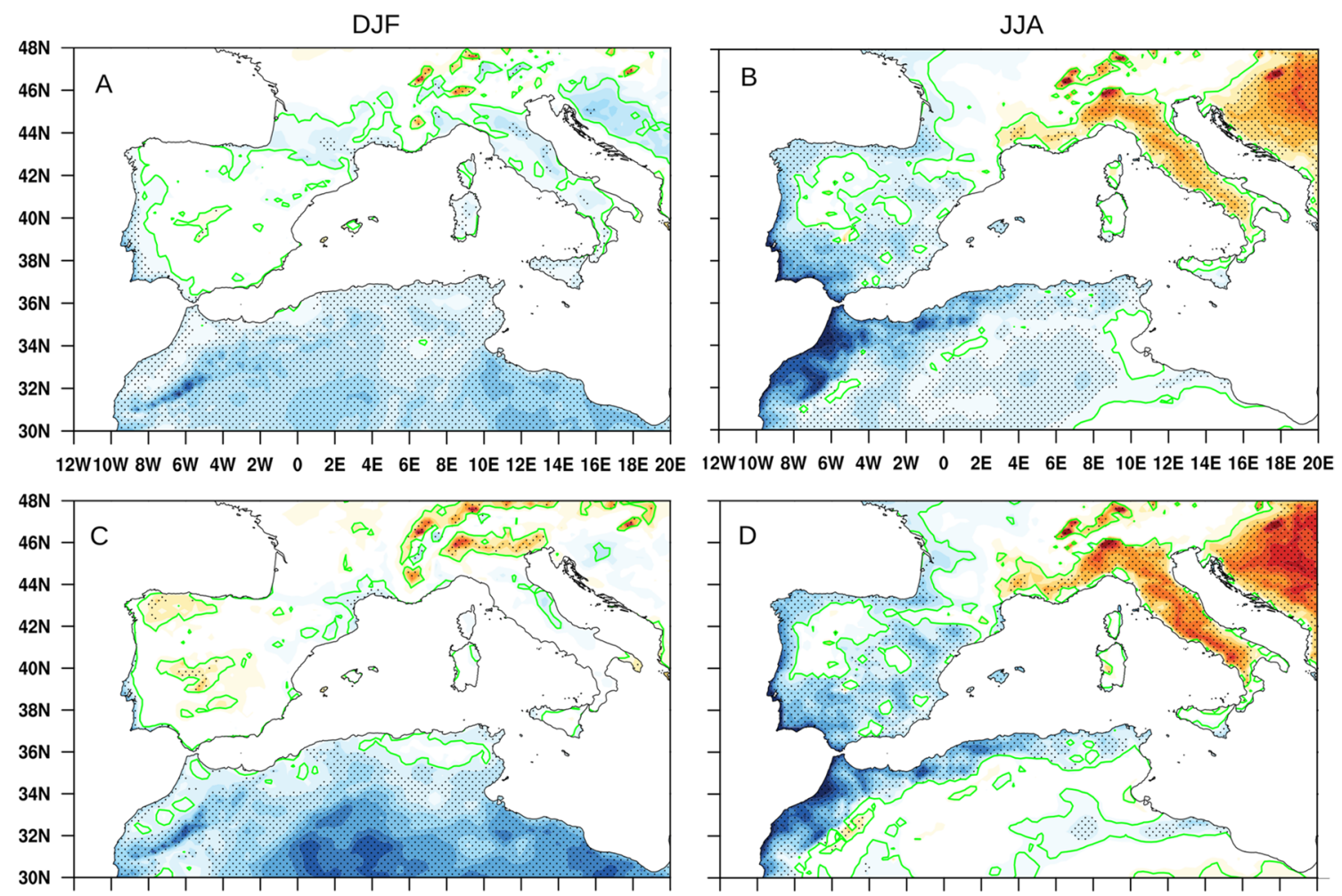

12W10W 8W 6W 4W 2W 0 2E 4E 6E 8E 10E 12E 14E 16E 18E 20E
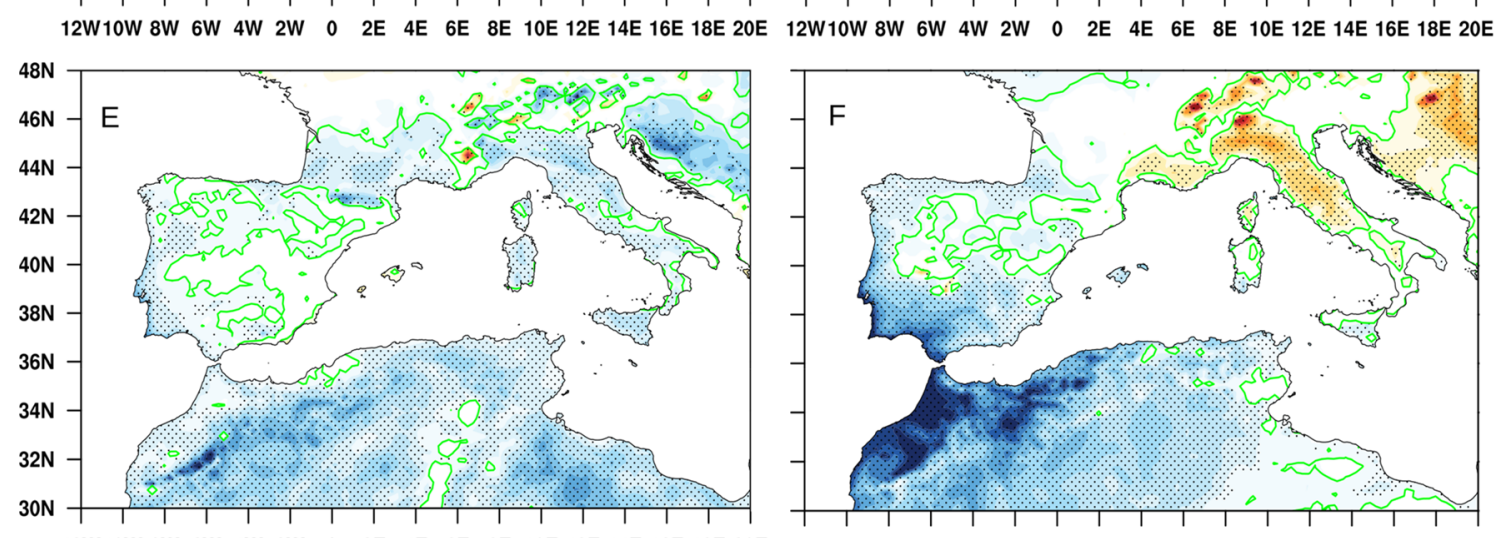

12W10W 8W 6W 4W 2W 0 2E 4E 6E 8E 10E 12E 14E 16E 18E 20E 12W10W 8W 6W 4W 2W 0 2E 4E 6E 8E 10E 12E 14E 16E 18E 20E

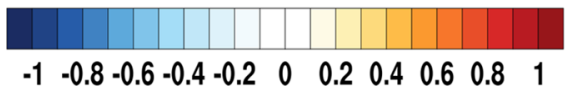

Fig. 5 Seasonal differences of future delta changes $(\Delta)$ of 2-m air temperature between ROM and REMO (delta = future i.e., 2070-2099 minus present i.e., 1976-2005; RCP 8.5 scenario). $\Delta \mathrm{T} 2 \mathrm{M}$ (a and b), $\triangle$ TMAX (c and d), and $\triangle$ TMIN (e and f). Positive values indicate that ROM predicts a greater temperature increase than REMO and negative values the opposite. Black dots and green lines indicate that differences between ROM and REMO are statistically significant at 95\% and $75 \%$ level, respectively. Positive values indicate that ROM predicts a greater temperature increase than REMO and negative values the opposite. Winter plots are shown in the left column and the summer ones in the right column 
as well as the areas where these differences are statistically significant using t-tests: the dotted regions mark the points where these differences are significant at the 95\% level. Green lines mark the regions where the differences are significant at the $75 \%$ level. Starting from winter, we observe that the $\Delta \mathrm{T} 2 \mathrm{M}$ is slightly smaller in the coupled run (about $0.5^{\circ} \mathrm{C}$ ) in many coastal areas (Fig. 5a; the corresponding spatial averages are presented in Table 1). This effect is more pronounced to the SW of the IP. In the center of the Meseta (its position is indicated with an arrow in Fig. 1SA), ROM's T2M experiences a slightly stronger increase (about $0.2^{\circ} \mathrm{C}$ ). In this season, $\triangle \mathrm{TMAX}$ is smaller in the coupled run over a narrower coastal area, especially over the SW of the IP, where the lowering of the $\triangle$ TMAX by the coupling is more pronounced, and to the NE of the IP (Fig. 5c). However, the coupling increases the $\triangle$ TMAX over a large part of the center, south and NW of the IP. The increase varies between 0.2 and $0.4{ }^{\circ} \mathrm{C}$ approximately. Regarding TMIN, it shows a more generalized pattern consisting of an overall delta decrease by the coupling of about $0.5^{\circ} \mathrm{C}$ over most of the IP (Fig. 5e). The $\triangle$ TMIN difference between ROM and REMO becomes more sharply along the Pyrenees, where the decrease due to coupling is close to $0.8^{\circ} \mathrm{C}$. We note that a common feature to all cases is a remarkable decrease in winter temperature climate change signal to the SW of the IP (Fig. 5a, c, e). Focusing now on the summer season, we realize that changes in the $\Delta \mathrm{T} 2 \mathrm{M}$ due to air-sea coupling present a similar regional distribution and magnitude for T2M, TMAX and TMIN (Fig. 5b, d, f). In all cases, the delta is reduced importantly over most of the IP. As in winter, this decrease is more remarkable over the $\mathrm{SW}$ portion of the IP, where the delta decrease varies between 0.8 and $1{ }^{\circ} \mathrm{C}$, approximately. On the other hand, coupling leads to a subtle increase of the delta of the temperature over the central portion of the IP and high mountain chains such as the Pyrenees. Notwithstanding, this effect is more localized and is not greater than about $0.5^{\circ} \mathrm{C}$.

In winter, the differences between delta changes in the coupled and uncupled runs are significant at $95 \%$ for T2M and TMAX near the western coast and the center of the IP. For TMIN, delta differences are significant at $95 \%$ over a larger area of the peninsula with the exception of (roughly speaking) the center and the east of the IP. In summer, however, the differences between the delta changes in ROM and REMO runs are statistically significant at $95 \%$ almost everywhere in the IP, but not in the central portion of the peninsula. From the results presented so far we can conclude that both the coupled and uncoupled simulations project a 2-m air temperature rise with respect to the present-day situation for the end of the twenty-first century. The warming is particularly marked in summer, especially in the interior parts of the IP. However, ROM predicts a generally smaller air temperature rise than REMO. This reduction in the warming is particularly remarkable in summer, in the nearshore areas, especially over the SW of the IP. This highlights that regional air-sea interactions play a more relevant role for temperature in summer. In this reduction, an important role is played by the modification of the heat fluxes through the interactive ocean, as part of the energy coming from the atmosphere is advected or mixed down to the deeper ocean, changing the turbulent heat fluxes calculated by the stand alone atmospheric model (e.g., Li et al. 2014; Kelemen et al. 2019).

\subsubsection{Precipitation changes due to air-sea coupling}

Figure $6 \mathrm{a}$ and $\mathrm{b}$ show the precipitation delta change $(\Delta \mathrm{prec})$ for REMO in winter and summer. In winter, as in ROM, precipitation shows a remarkable increase in the $\mathrm{NW}$ of the IP, which extends towards the interior, and a decrease to the northern and eastern flanks of the IP (Fig. 6a). In particular, changes are of a greater magnitude than in ROM, especially in the case of the precipitation increase that occurs to the NW sector of the IP (see also Fig. 4c). The amplified signal of precipitation changes in REMO can also be appreciated in Fig. 6c, which shows the difference of $\Delta$ prec between ROM (coupled) and REMO (uncoupled). We see that winter precipitation delta changes in REMO can be up to $1 \mathrm{~mm} /$ day higher than in ROM. This is consistent with changes in the North Atlantic large-scale circulation inherent to coupling. However, the changes in the regional advection cannot fully explain these differences, as can be seen in Fig. 2S. The downscaling signal in REMO reflects the differences in model physics and horizontal resolution and the coupling modifies this downscaling signal in regions where it affects the heat fluxes or the oceanic circulation (this aspect will be tackled in detail in the Discussion). On the contrary, delta changes along the Mediterranean shore indicate a subtle, but larger, precipitation decrease in REMO with maximum delta differences of about $0.6 \mathrm{~mm} /$ day near the Gulf of Valencia. Differences in convective precipitation that explain this behavior are probably linked to dissimilarities in the Mediterranean SST (sea-surface temperature) delta changes simulated by ROM and MPI-ESM.

In summer, precipitation is scarce and so are future changes in REMO (Fig. 6b). As in ROM, the IP experiences a general drying in the REMO stand-alone simulation, this being more pronounced along the northern flank of the IP, where the decrease can reach values close to $0.8 \mathrm{~mm} /$ day. This notwithstanding, the summer precipitation averaged over the IP in REMO is greater than in ROM i.e., $0.44 \mathrm{~mm} /$ day vs $0.33 \mathrm{~mm} /$ day (note that the present-day precipitation is different in REMO and ROM). Differences in $\Delta$ prec between REMO and ROM are small, but are more noticeable in the north and eastern sectors of the IP (Fig. 6d). As stated above, the causal mechanisms of the impact of coupling on 
DJF

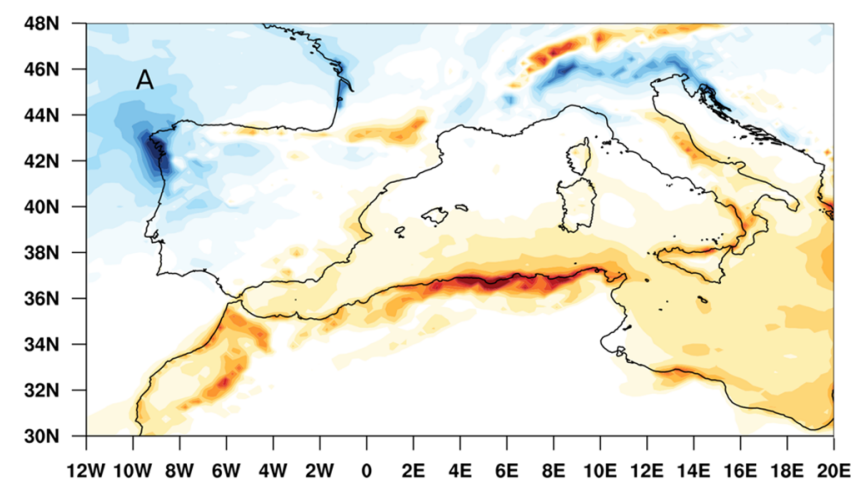

JJA

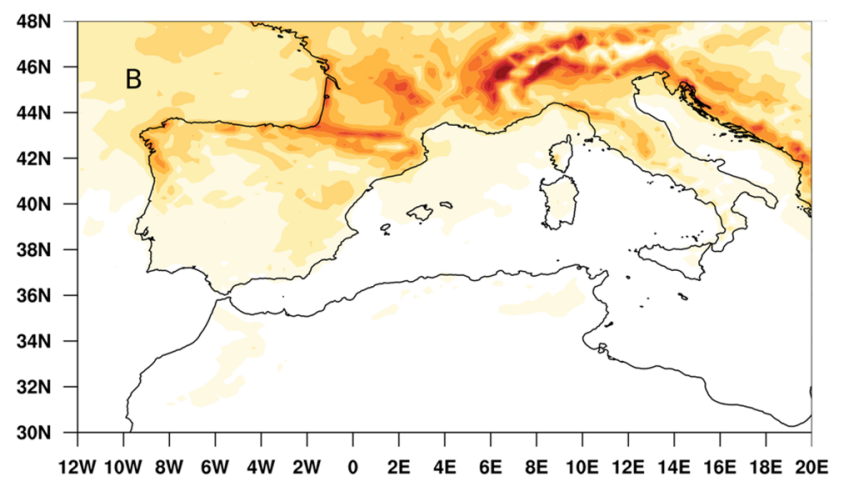

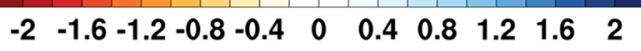

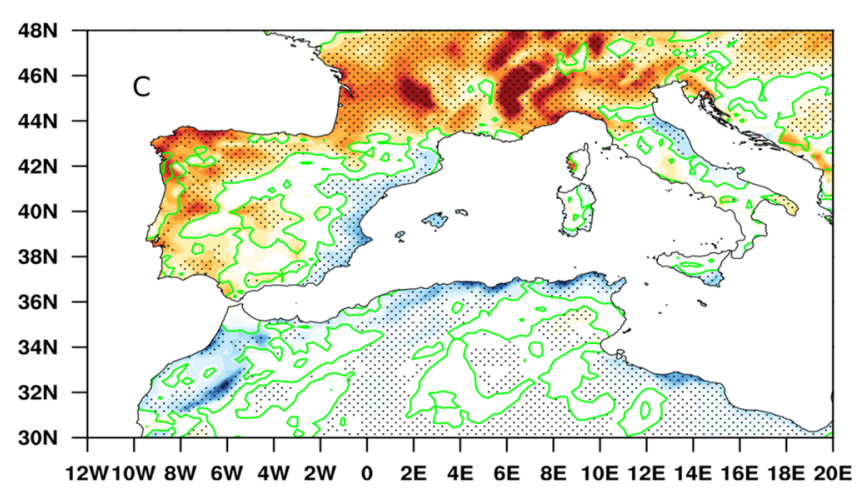

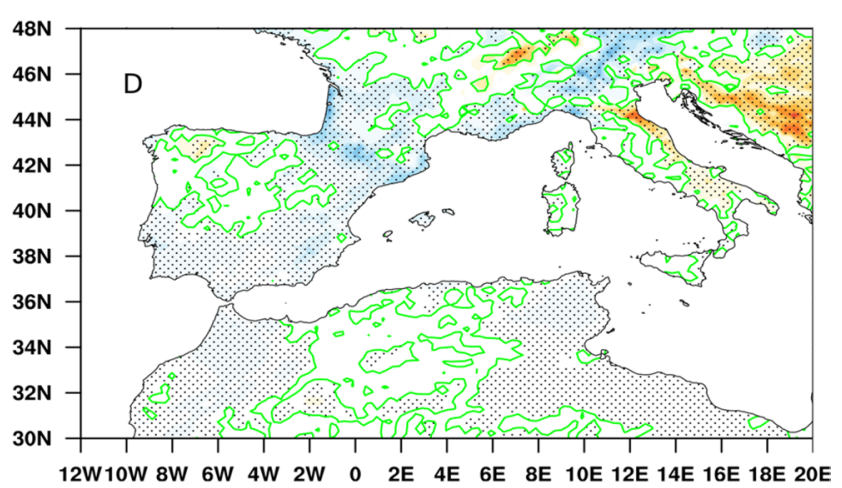

12W10W 8W 6W 4W 2W 0 2E 4E 6E 8E 10E 12E 14E 16E 18E 20E

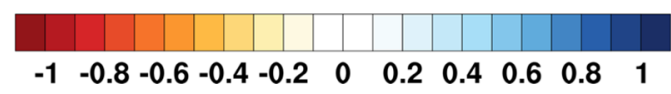

Fig. 6 Panels a and b: Winter (a) and summer (b) differences of future (RCP8.5 scenario) and present precipitation in REMO. Positive values correspond to a precipitation increase in the future and negative values the opposite. Panels $\mathbf{c}$ and $\mathbf{d}$ : Winter (c) and summer (d) delta changes $(\Delta)$ of precipitation between ROM and REMO.

winter and summer $\Delta$ prec over the IP will be tackled in more detail in the Discussion.

Regarding the significance of the differences between the coupled and uncoupled precipitation delta changes, we note that, in winter, these are significant at $95 \%$ almost everywhere in the IP with the exception of its central domain. In summer, differences are significant at $95 \%$ over a vast extension of the IP, but not within the NW.

\subsection{How sensitive is the future climate of the IP to changes in the emission scenario selected?}

So far we have focused on the analysis of the future climate of the IP assuming the RCP8.5 emission scenario. This high emission scenario was chosen as one of the worst case emissions outcomes, which leads in the long term to high
Black dots and green lines in panels $\mathbf{c}$ and $\mathbf{d}$ indicate that differences between ROM and REMO are statistically significant at $95 \%$ and $75 \%$ level, respectively. Positive values indicate that ROM projects a stronger precipitation increase and negative values the opposite

energy demand and greenhouse gas emissions in absence of climate change policies (Riahi et al. 2011). However, at this point, it is of interest to know how robust the findings about the climate on the IP at the end of the twenty-first century are, as well as the associated changes with respect to the present situation, when a weaker radiative forcing is applied. In particular, we now study the climate of the IP under the stabilization scenario RCP4.5, which allows us to study the climate system response to stabilizing the anthropogenic components of radiative forcing. As we intend to analyze the impact of having a different scenario, we do not explore the impact of coupling, which we expect to be less in this lower-radiative forcing scenario. We do the subsequent analysis for the coupled simulations with ROM. In winter, $\mathrm{T} 2 \mathrm{M}$ presents a similar magnitude and regional distribution under the RCP4.5 than in the equivalent simulation with 
the RCP8.5 scenario (Figs. 1a, 7a). However, as somewhat expected, T2M is lower in the RCP4.5 scenario and this can be clearly appreciated over the most prominent mountain chains of the IP, such as the Pyrenees, the Cantabric Cordillera, the Central System or the Betic Cordillera, among others. Changes with respect to the present situation are now more modest (Figs. 1c, 7c). T2M does not go up more than $1-2{ }^{\circ} \mathrm{C}$ and the increase over the Mediterranean Sea is particularly small. Only near the Balearic Islands, the Tyrrhenian Sea and near the Lybian coast T2M increases to a larger extent, this being smaller than $1^{\circ} \mathrm{C}$ (see corresponding averages in Table 1). In summer, T2M in RCP4.5 also presents a similar spatial distribution as in the RCP8.5, but it is less extreme (Figs. 1b, 7b). This can be appreciated over the
IP, especially within the Guadalquivir Valley. In line with what we found for the RCP8.5 scenario, the summer increase in T2M is larger than in winter (Figs. 1d, 7d). Furthermore, $\mathrm{T} 2 \mathrm{M}$ increases over the peninsula and the temperature rise is particularly important over the Meseta and south of Spain. In this case, however, the maximum increase of T2M does not exceed $3-4{ }^{\circ} \mathrm{C}$. Interestingly, different to the winter situation, T2M experiences a generalized increase above the Mediterranean Sea. The T2M rise over the Mediterranean Sea is more subtle than in the RCP8.5 case and is not greater than about $2{ }^{\circ} \mathrm{C}$.

Under RCP4.5, the winter precipitation shows a similar regional distribution that under RCP8.5, with the strongest precipitation to the NW and to the N of the IP (Figs. 4a, 8a).

\section{DJF}

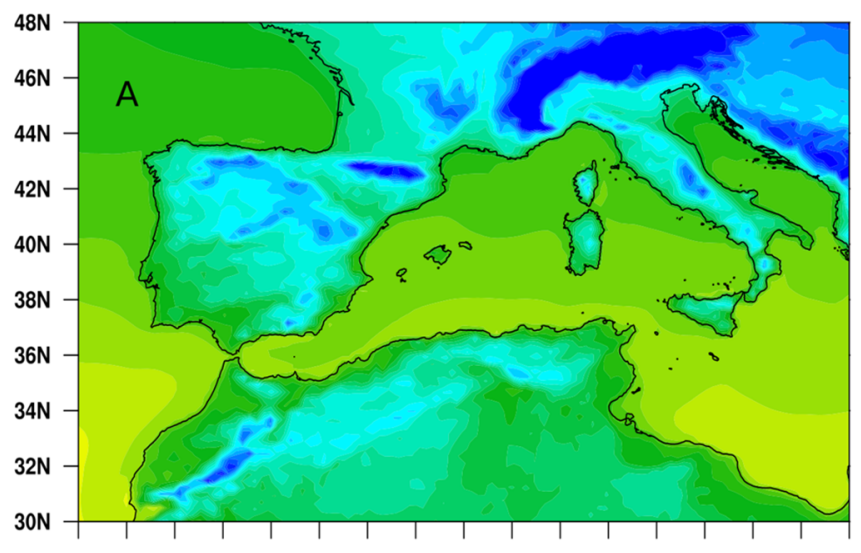

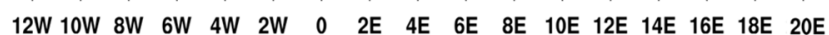

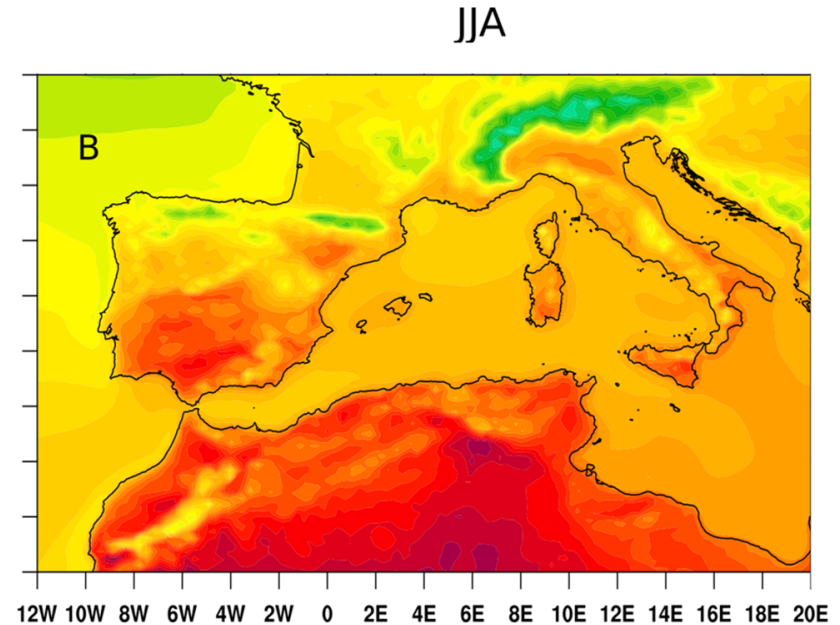

$\begin{array}{lllllllllllllllllll}12 W & 10 W & 8 W & 6 W & 4 W & 2 W & 0 & 2 E & 4 E & 6 E & 8 E & 10 E & 12 E & 14 E & 16 E & 18 E & 20 E\end{array}$

\section{$\begin{array}{llllllllll}0 & 4 & 8 & 12 & 16 & 20 & 24 & 28 & 32 & 36\end{array}$}
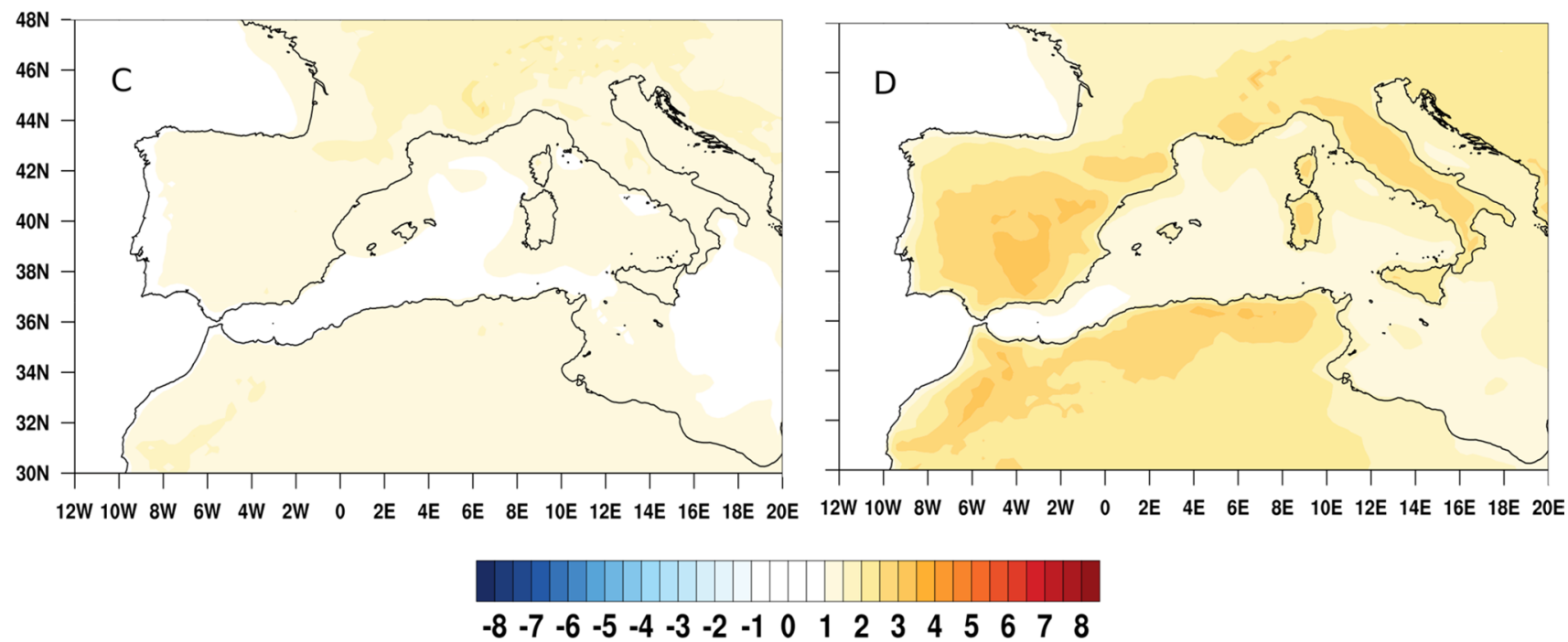

Fig. 7 Panels a and b: Seasonal averages of 2-m air temperature (T2M), in ${ }^{\circ} \mathrm{C}$, computed for the future (RCP4.5 scenario) in ROM. Panels $\mathbf{c}$ and $\mathbf{d}$ : Seasonal differences of future and present T2M in
ROM for the RCP4.5 scenario. Positive values indicate a T2M rise in the future and negative values the contrary. Winter plots are shown in the left column and the summer ones in the right column 


\section{DJF}

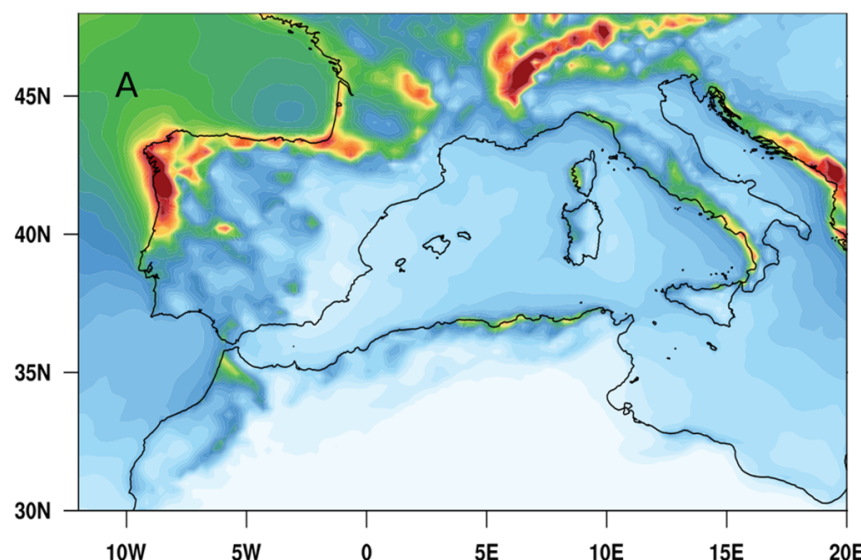

JJA

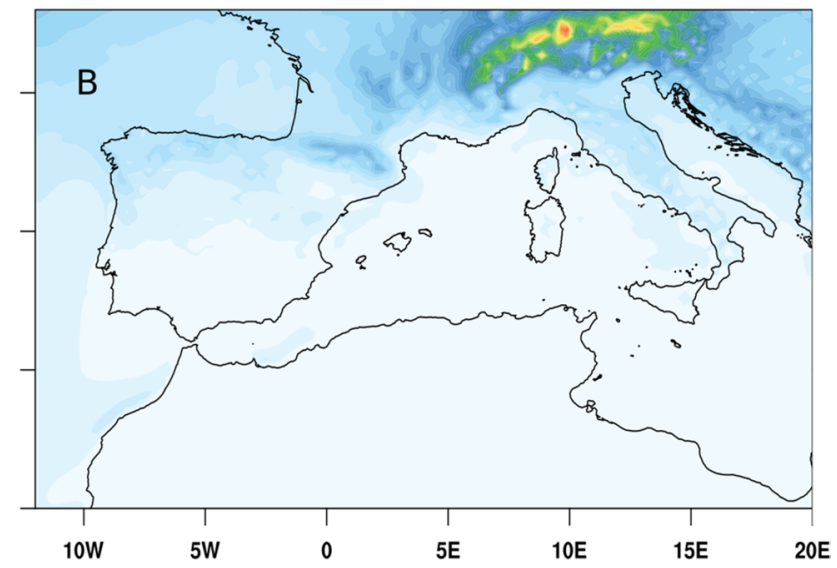

$\begin{array}{lllllllllll}0 & 1 & 2 & 3 & 4 & 5 & 6 & 7 & 8 & 9 & 10\end{array}$
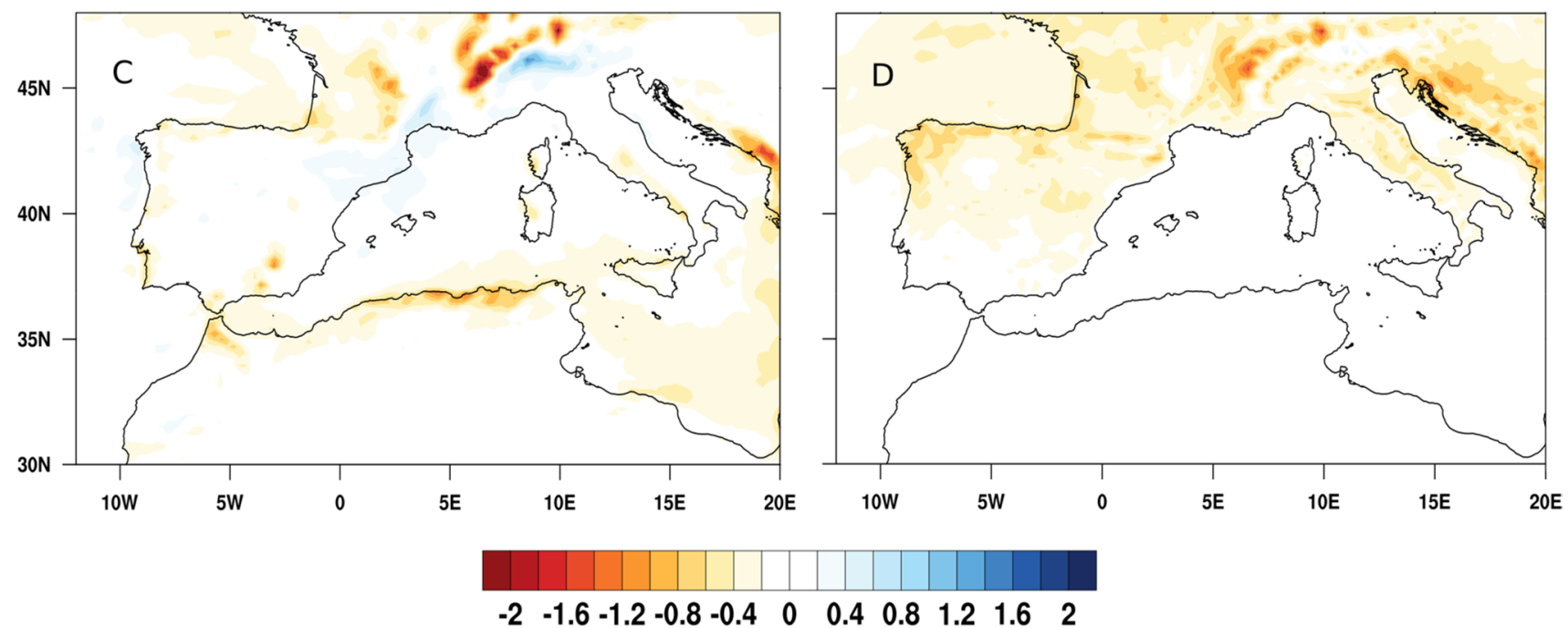

Fig. 8 Panels a and b: Seasonal averages of precipitation, in $\mathrm{mm} /$ day, computed for the future (RCP4.5 scenario) in ROM. Panels $\mathbf{c}$ and $\mathbf{d}$ : Seasonal differences of future and present precipitation in

In more detail, changes in precipitation under RCP4.5 show a subtle decrease over the north, west and southern flanks of the peninsula (Fig. 8c). Precipitation decreases remarkably over the Betic System, up to $1.5 \mathrm{~mm} /$ day, and slightly increases to the NE of the peninsula, with values close to $0.5 \mathrm{~mm} /$ day. Besides differences in the magnitude of precipitation changes, which are larger in the RCP8.5 scenario, other relevant differences can be spotted (Figs. 4c, 8c). In particular, precipitation decreases now to the NW of the IP, whilst this area experienced a marked precipitation increase in the RCP8.5. This is the result of a slightly lower SST increase inherent to the prescription of a less radiative forcing which, in turn, causes a decrease of oceanic latent heat flux into the atmosphere and thus in precipitation (this aspect
ROM (RCP4.5). Positive values correspond to a precipitation rise in the future and negative values the opposite. Winter plots appear in the left column and the summer ones in the right column

will be tackled in the Discussion). In summer, precipitation over the IP is scarce and shows a marked north-to-south gradient, with higher values to the north (Fig. 8b). The regional distribution of summer rainfall is therefore similar to that found for the RCP8.5 case (Fig. 4b). Paying attention to the precipitation changes we note that the IP features a generalized increase of the area under dry conditions (Fig. 8d). This is more marked to the north of the peninsula, especially along the mountain chains, and becomes weaker to the south. This pattern was also found for the RCP8.5 case, although now the magnitude of the changes is a bit smaller.

Therefore, we can conclude that the prescription of the RCP4.5 scenario does not have a first-order influence on the regional distribution of T2M in the future, nor in the spatial 
distribution of the corresponding changes with respect to the present-day situation, but has an influence on their magnitude. In particular, changes in T2M are less sharp than in the RCP8.5 case (see Table 1) and this result is in line with the sensitivity study of Garrido et al. (2020), who find that future warming over the IP with the WRF model is less pronounced with the RCP4.5 scenario. Furthermore, precipitation changes in the IP when the RCP4.5 scenario is prescribed are rather small. However, an interesting difference between the two scenarios is that under RCP8.5 a remarkable precipitation increase occurs in the NW portion of the IP, while it decreases under RCP4.5. This difference may be related to a different SST (latent heat flux) over the North Atlantic which causes a reduction of the large-scale precipitation (see Fig. 9). The specific averages over the IP and the corresponding projected changes computed for the RCP4.5 scenario are presented in Table 1. Therefore, the differences in delta changes coupled-uncoupled includes both the effect of the modulation of the radiative forcing by the coupling and the nonlinear effects due to changes in the ocean circulation.

\subsection{MPI-ESM vs ROM}

In previous works it has been shown that ROM reproduces a different climate change signal than the driving global climate model (Limareva et al. 2017; Sein et al. 2020a). For instance, in Sein et al. (2020a), it is found that although the climate change signal over Europe in ROM is largely determined by MPI-ESM, ROM presents many interesting features that are not found in MPI-ESM and which are largely explained by its higher resolution. The advantages of the coupled downscaling are especially clear when it is necessary to study a region where high resolution is necessary and the coupling plays a determinant role. This is the case of the Mediterranean Sea, where ROM has shown a good performance in studying oceanic and atmospheric phenomena that cannot be studied in MPI-ESM due to the lower resolution and are better represented when coupling is taken in account (e.g., Parras-Berrocal et al. 2020). In this section we concentrate on the study of the differences between the climate change signal from ROM and MPI-ESM, respectively, over the IP. In MPI-ESM, T2M experiences a generalized increase in the future which is more pronounced in the summer season (compare Figs. 1c, d, 10a, b). In more detail, the winter climate change signal in MPI-ESM shows a clear east-west gradient with the greatest values to the east, a feature that also can be found in ROM (compare Figs. 1c, 10d). However, details related to the high resolution in ROM cannot be appreciated in MPI-ESM e.g., the effect of topography on $\mathrm{T} 2 \mathrm{M}$. This drives regional differences in the magnitude of the projected changes in T2M. In summer, whilst both agree on a remarkable increase in the interior of the IP, ROM reproduces a slightly different regional pattern probably due to its enhanced horizontal resolution (Figs. 1d, 10b).

Regarding precipitation, important differences are noticed between ROM and MPI-ESM (Figs. 4c, d, 10c). In winter, as in ROM, MPI-ESM projects a future increase in precipitation to the NW of the IP (Fig. 10c). In agreement with ROM, MPI-ESM features a precipitation decrease to the SE of the Peninsula. Besides changes in the regional distribution of precipitation in winter, the magnitude of the change is much smaller in MPI-ESM, where it does not exceed $0.4-0.8 \mathrm{~mm} /$ day. Focusing on the summer season, similarly to ROM, the precipitation in MPI-ESM decreases over all the IP, with a marked north-south gradient, with values of the order of

DJF
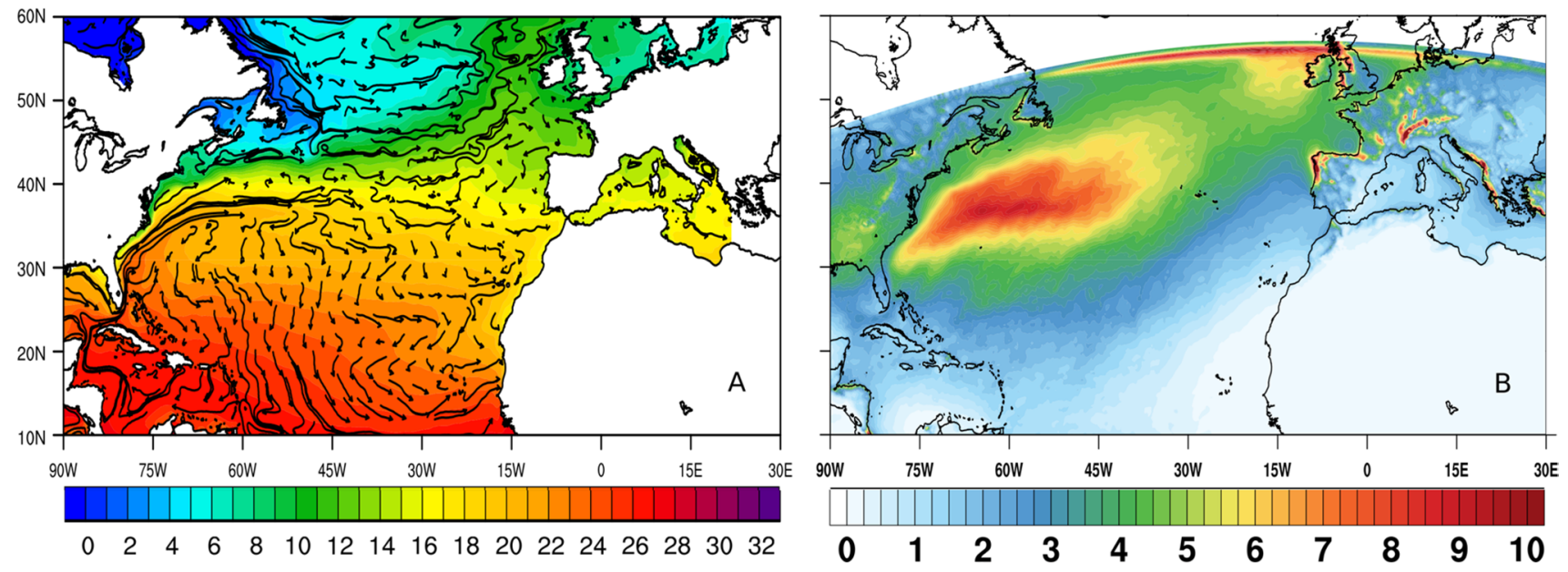

Fig. 9 Panel a: Winter averages of SST (colors; ${ }^{\circ} \mathrm{C}$ ) and geostrophic circulation (arrows; $\mathrm{cm} / \mathrm{s}$ ). Panel b: Winter precipitation (mm/day). Plots are constructed for the future (RCP4.5 scenario) over the North Atlantic in ROM 
DJF

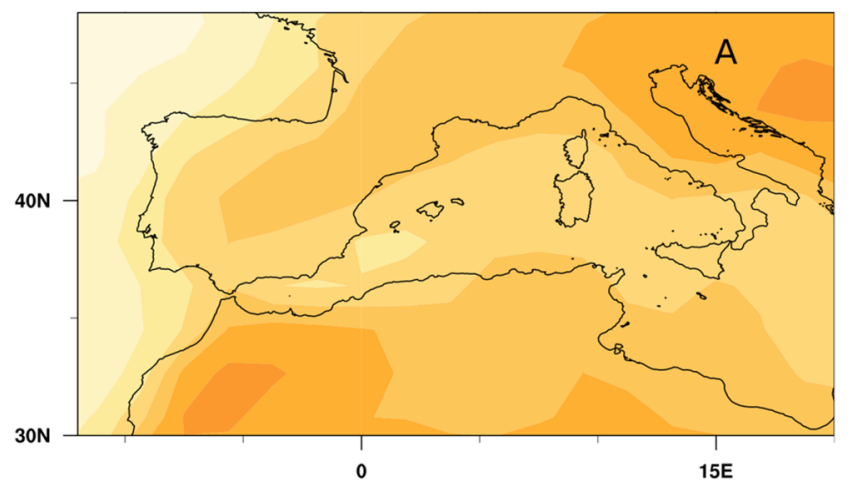

JJA

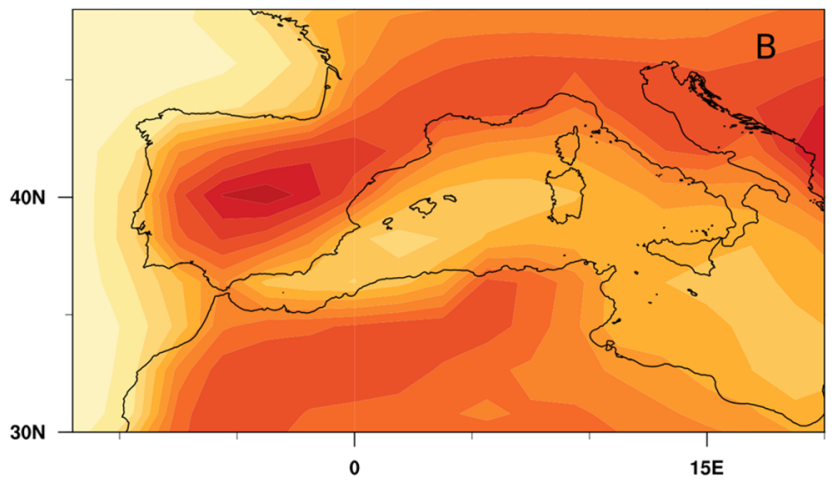

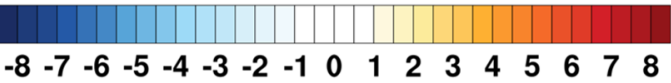
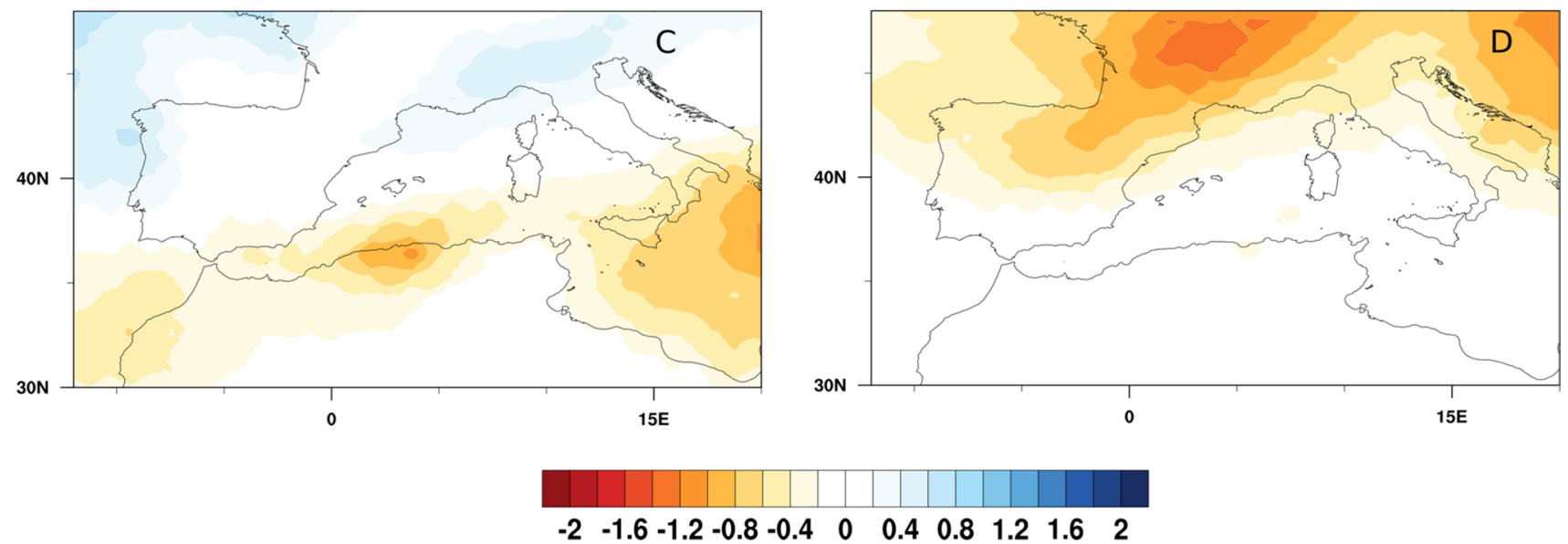

Fig. 10 Seasonal differences of future (RCP8.5 scenario) changes of $\mathrm{T} 2 \mathrm{M}\left({ }^{\circ} \mathrm{C}\right.$; panels $\mathbf{a}$ and $\left.\mathbf{b}\right)$ and precipitation ( $\mathrm{mm} /$ day; panels $\mathbf{c}$ and d) for MPI-ESM. Positive values indicate a future increase in T2M

$0.8 \mathrm{~mm} / \mathrm{d}$ over the north, while in the south the decrease is of the order of $0.1 \mathrm{~mm} /$ day (Fig. 10d). However, the spatial distribution of the decrease in ROM shows the imprint of the orographic features, which are not visible in MPI-ESM (see also Fig. 4d). Results highlight that regional differences in precipitation cannot only be linked to spatial resolution, but also may be related to differences in the coupled model's physics and dynamics. For a quantification of the average values of T2M and precipitation over the IP we refer the reader to Table 1.

The differences in the climate change signal from ROM and MPI-ESM can also be seen in Fig. 11, which shows the evolution of the annual-mean time series of T2M and precipitation over the IP for the RCP8.5 scenario during the twenty-first century. T2M shows in both cases a clearly increasing trend from 2000 to 2099, with a qualitatively similar interannual variability (Fig. 11a). However, in line with what is shown in or precipitation and negative values the opposite. Winter plots are shown in the left column and the summer ones in the right column

Fig. 10, T2M is higher with MPI-ESM than with ROM. Focusing on precipitation, we note a slightly decreasing trend from 2000 to 2099 in MPI-ESM and ROM (Fig. 11b). The signal from both is characterized by a large interannual variability being, in general, ROM slightly drier than MPI-ESM. These results put forward that ROM is able to generate a different climate change signal relative to the driving global model MPIESM and therefore, the added value of regionalization. The climate signal provided by REMO under the RCP8.5 scenario and MPI-ESM and ROM under the RCP4.5 scenario is shown in Fig. $3 \mathrm{~S}$ of the Supplementary Material. 

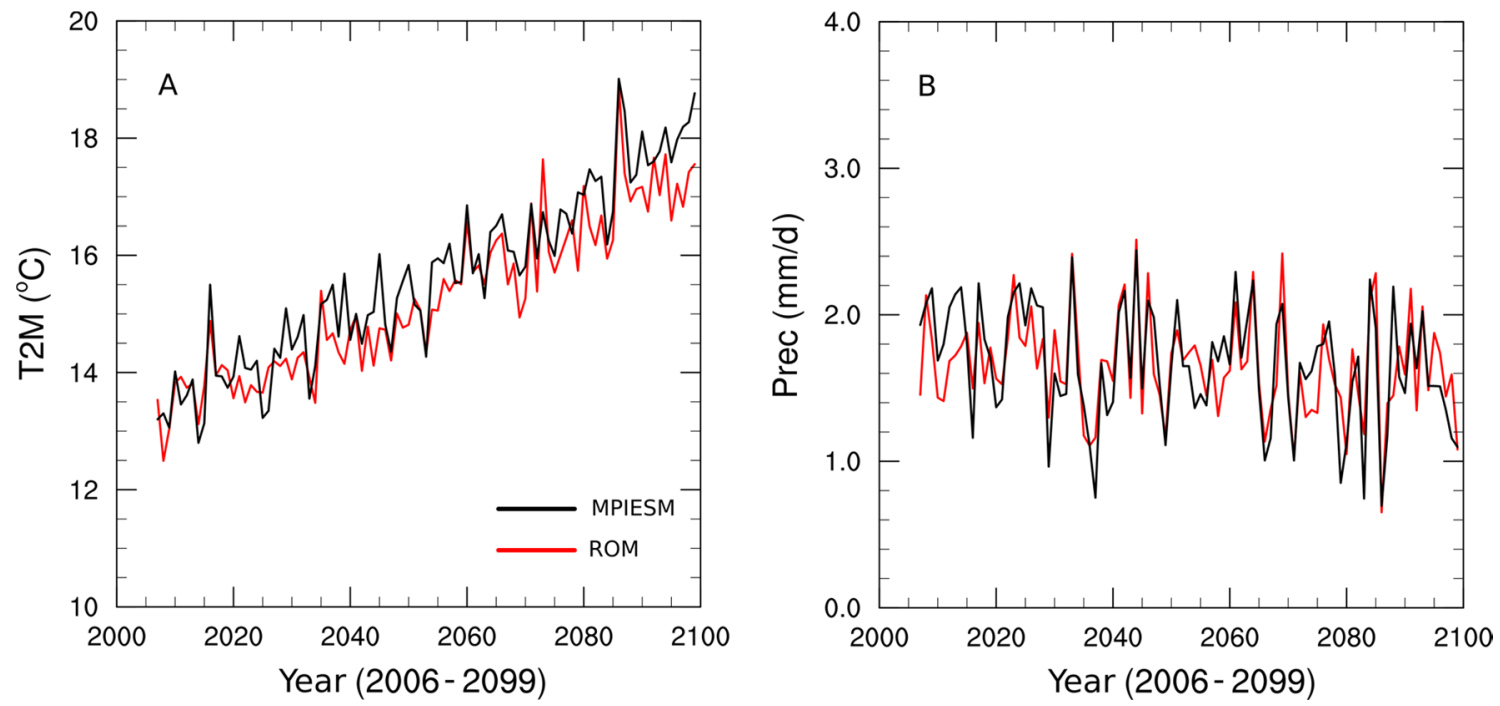

Fig. 11 Annual time series of 2-m air temperature $\left({ }^{\circ} \mathrm{C}\right.$; panel a) and precipitation (mm/day; panel b) averaged over the IP for MPI-ESM (black lines) and ROM (red lines) under the RCP8.5 scenario for the 2006-2099 time period

\section{Discussion}

In Sects. 4.1 and 4.2 we aim to understand the driving mechanisms for the differences in the climate change signal between the coupled and uncoupled runs in terms of T2M and precipitation under the RCP8.5 scenario. Although in a first approximation we can assume that the differences in the simulated variables induced by the coupling are the same in the present and in the future, they can be modulated by non-linear effects, mainly in the oceanic component. For instance, the higher resolution in the regional coupled model leads to a change in the path of the North Atlantic Current that is different than in the driving Global Model. This leaves a significant imprint on the coupled-uncoupled differences in the future climate. Therefore, the differences in delta changes between the coupled and the uncoupled simulations include both the effect of the modulation of the radiative forcing by the coupling and the non-linear effects due to changes in the ocean circulation.

\subsection{What causes the temperature changes observed in the Iberian Peninsula?}

The climate of the IP is strongly influenced by the North Atlantic large-scale atmospheric and oceanic circulation, which are in first-order controlled by the warm Gulf Stream and the North Atlantic Current (Minobe et al. 2008; Keeley et al. 2012; Cabos et al. 2020). In winter, the surface current systems simulated by ROM and MPI-ESM display some important differences (Fig. 12a, c). In both simulations, the Gulf Stream and the North Atlantic Current (the continuation of the Gulf Stream towards the NE), can be distinguished (see Fig. 1SC of the Supplementary Material). These currents advect heat towards western Europe and have an imprint on European climate (Buckley and Marshall 2016). Their paths can be recognized by the development of characteristic, strong SST fronts. We note that in MPI-ESM these currents are wider than in ROM (Fig. 12a, c). Also, in MPI-ESM, the North Atlantic Current extends further east. A similar shift in the trajectories of these currents depending on the oceanic resolution has been found in Sein et al. (2018). These differences in the trajectory of the Gulf Stream and the North Atlantic Current in ROM and MPI-ESM cause the observed SST differences between the two (i.e., ROM minus MPI-ESM) by the end of the century under the RCP8.5 scenario (Fig. 12e).

This displacement of the North Atlantic current in ROM leads to positive SST differences along the warm current paths simulated in ROM and negative elsewhere, including the path of the currents simulated in MPI-ESM. As a result, ROM brings warm water to the North Western corner and the GIN (Greenland, Iceland and Norway) Seas (see also Fig. 1SC of the Supplementary Material), influencing not only the climate of these regions, but also the large-scale atmospheric circulation. In ROM, the North Atlantic Current extends further north than in MPI-ESM and the subsequent recirculation branch favors the development of a southward-flowing current that brings cold waters from high latitudes towards the coast of the IP (Fig. 12a; this aspect is also discussed in Cabos et al. 2020). In ROM, the Canary Current, which can be regarded as a southward branch of the North Atlantic Current is weaker than in MPI-ESM (see Fig. 1SC). As a consequence of this reduction of the transport of colder water by the Canary Current, the SST 

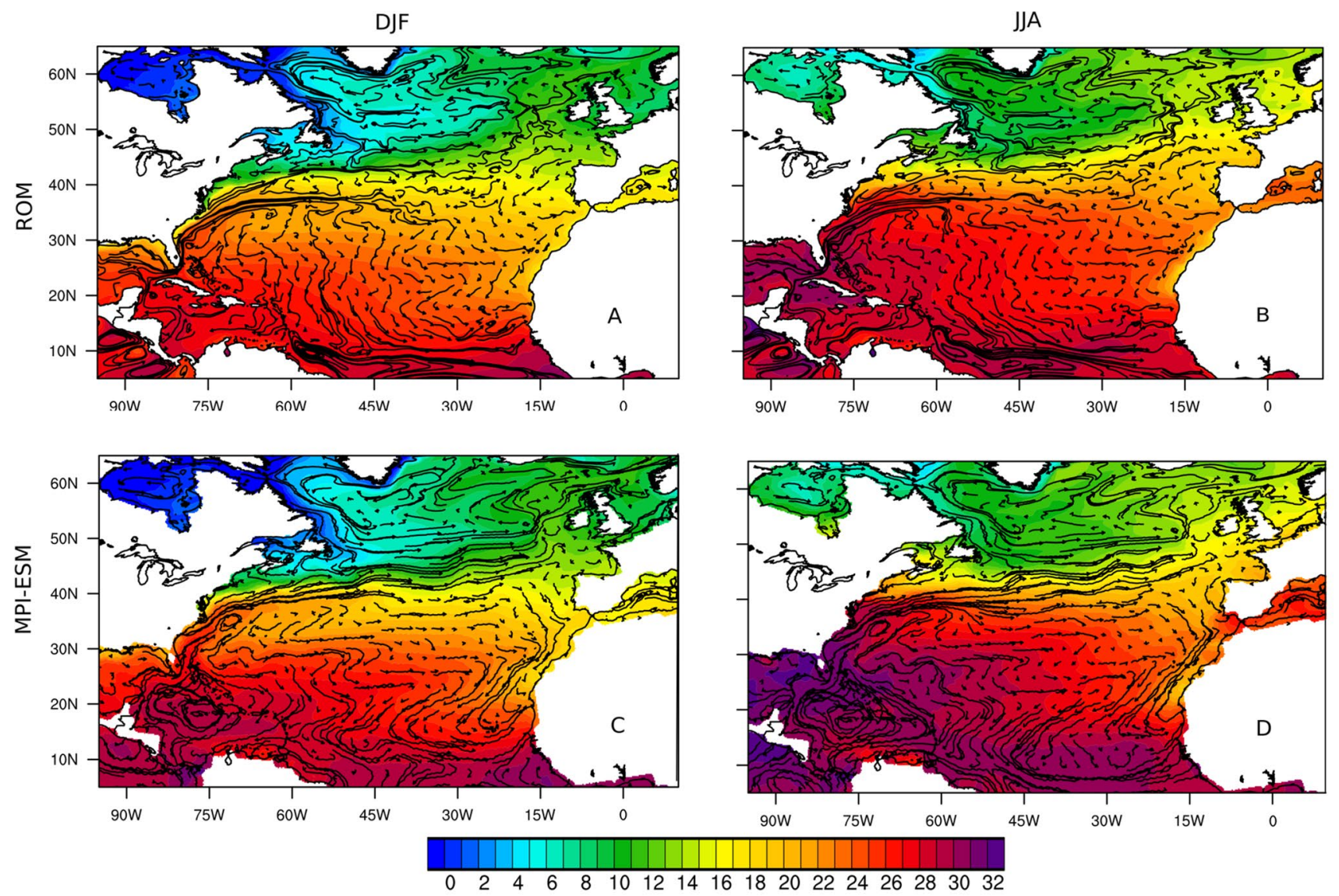

$\begin{array}{llllllllllllllllll}0 & 2 & 4 & 6 & 8 & 10 & 12 & 14 & 16 & 18 & 20 & 22 & 24 & 26 & 28 & 30 & 32\end{array}$
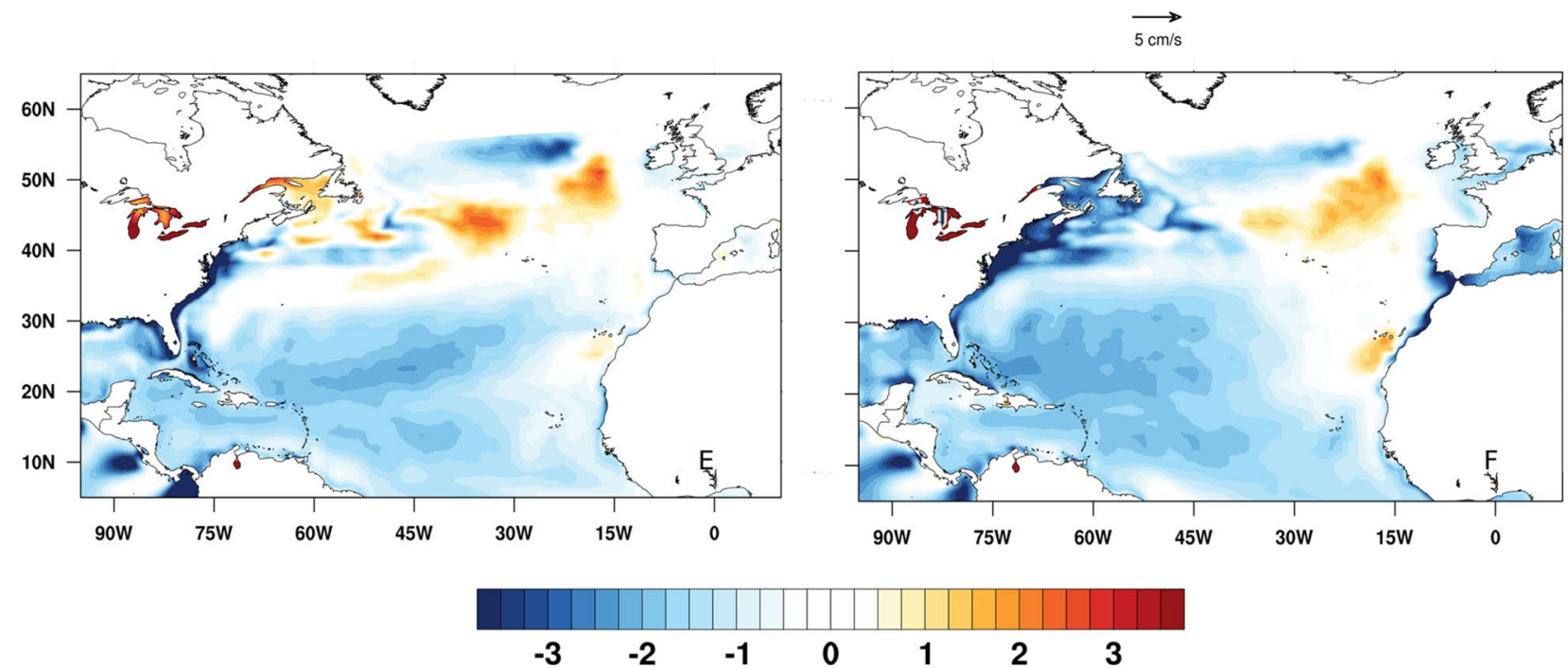

Fig. 12 Panels a-d: Seasonal averages of sea-surface temperature $\left({ }^{\circ} \mathrm{C}\right)$ and geostrophic ocean circulation $(\mathrm{cm} / \mathrm{s})$ computed for the future time period assuming the RCP8.5 scenario with ROM (a, b) and MPI-ESM (C-D). Panels e, f: Seasonal averages of the differences between the future sea-surface temperature $\left({ }^{\circ} \mathrm{C}\right)$ from ROM and MPI-

slightly increases along its path in ROM. In MPI-ESM, the Canary Current does not intake waters from latitudes northern than $40^{\circ} \mathrm{N}$. In turn, the SST, through air-sea fluxes, has
ESM (i.e., a minus c; b minus d). Positive values indicate that ROM temperature is higher and negative values the opposite. Winter plots are presented in the left column and the summer ones in the right column

an impact on the T2M, which closely resembles the surface temperature pattern (Fig. 13a, c, e; see also Cabos et al. 2020). Cold T2M anomalies are subsequently transported 

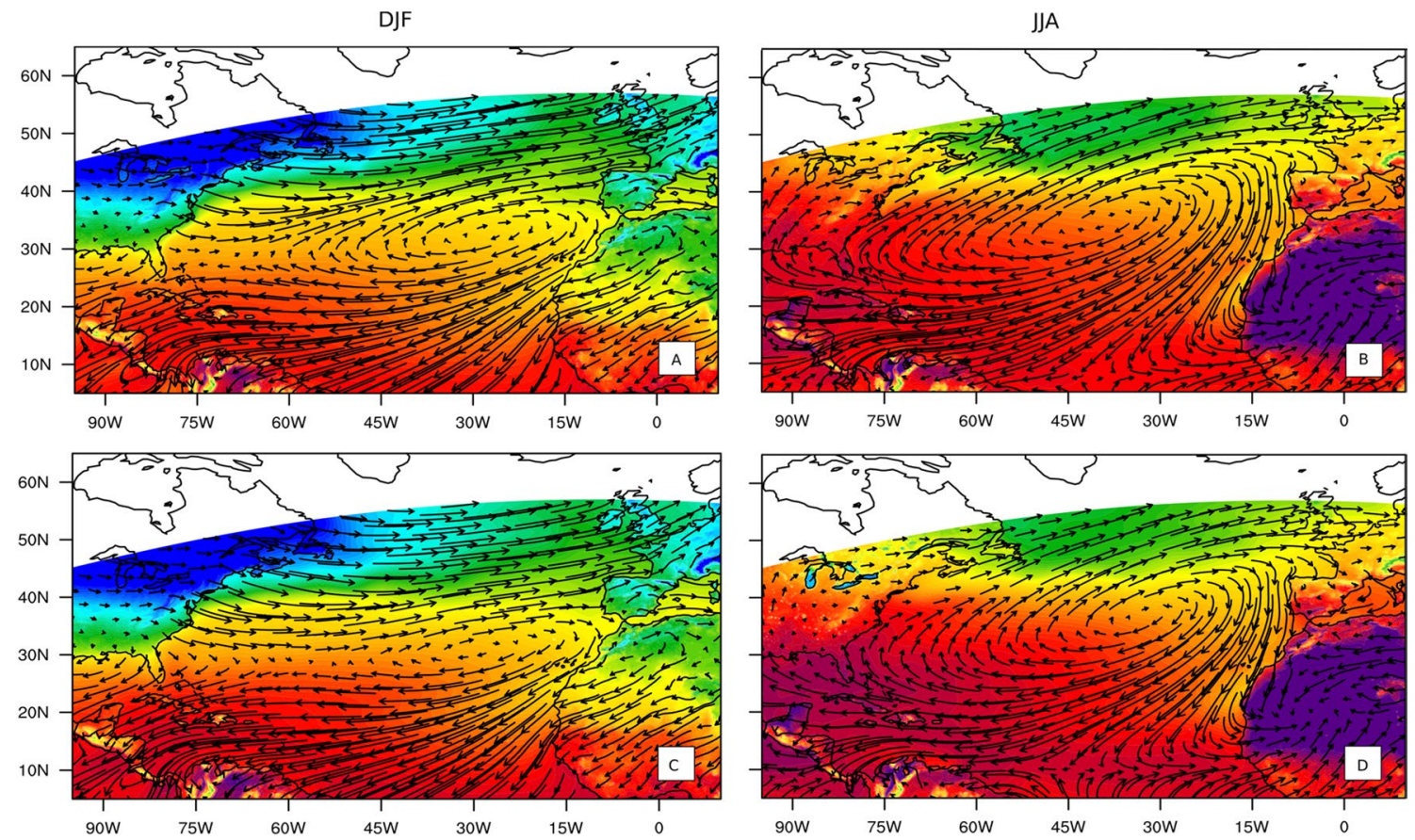

02246810121416182022242628303234
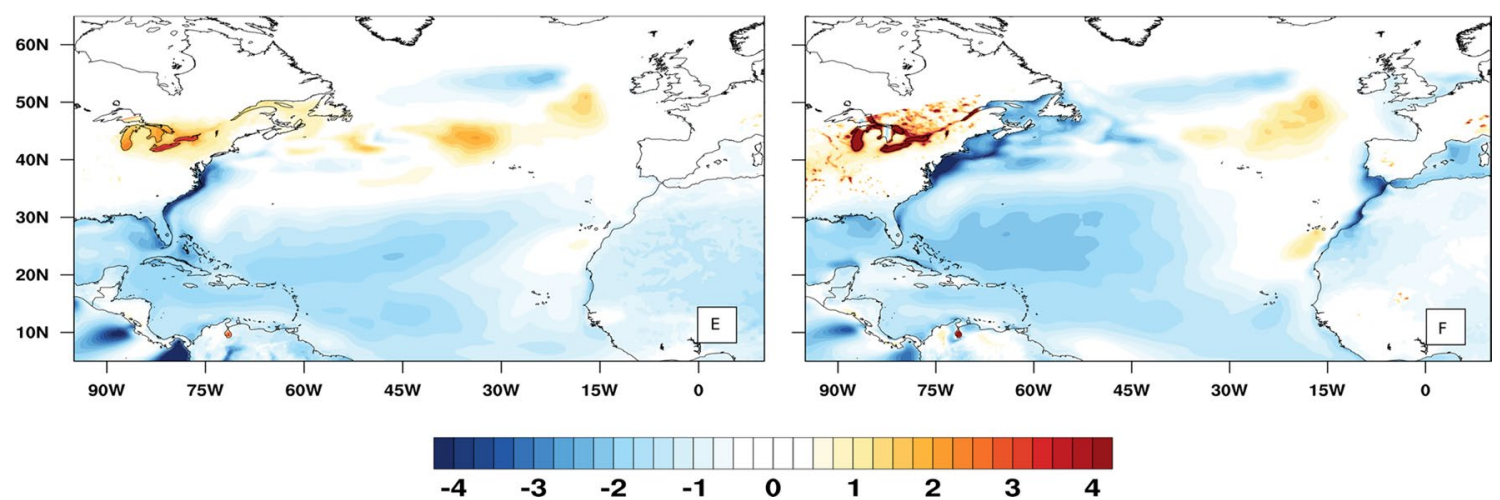

Fig. 13 This is equivalent to Fig. 12, but constructed for ROM and REMO for T2M ( ${ }^{\circ} \mathrm{C}$; colors) and 10-m wind speed (m/s; vectors)

towards the IP through the eastward branch of the Atlantic Anticyclone (Fig. 13). The effect is clear in Fig. 4S, where winter differences in $850 \mathrm{hPa}$ winds and T2M simulated by ROM and REMO for the 2070-2099 period are represented. This explains the colder T2M observed in ROM relative to the REMO, especially to the SW of the IP (see also Fig. 5a; Table 1). Winds and SST differences between the coupled and uncoupled runs near the IP can be observed in more detail in Fig. 14a, c, and e.

In summer, as in winter, the Gulf Stream and the North Atlantic Current are wider and flow further east in MPI-ESM than in ROM (Fig. 12b, d). Also, summer SST differences between ROM and MPI-ESM have a similar regional distribution as in winter (Fig. 12f). Whilst the SST has a clear imprint on T2M (Fig. 13b, d), the northward migration of the Azores anticyclone in summer makes the IP less sensitive to the Atlantic large-scale circulation (Cabos et al. 2020). The effect of the Atlantic large-scale circulation is mostly limited to the western flank of the IP, which is affected by strong southward-flowing winds associated with the Azores High which reinforce in summer (Soares et al. 2014; Rijo et al. 2017). In particular, the most remarkable lowering of the $\Delta \mathrm{T} 2 \mathrm{M}$ with ROM is observed over the western rim of the IP, especially over its SW portion (Fig. 5b). This may be driven by the along-shore, southward wind intensification which, in ROM, favors coastal upwelling of cold waters towards the surface within the south of Portugal. Due to the higher resolution of the oceanic component, ROM is able to simulate 
DJF

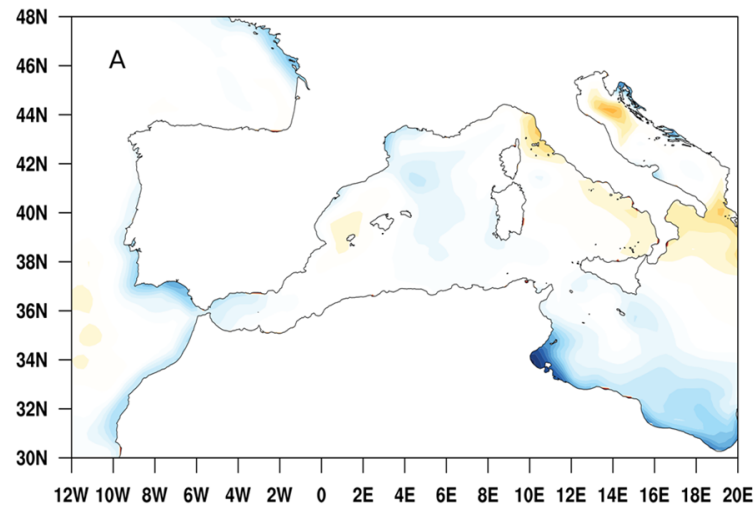

JJA

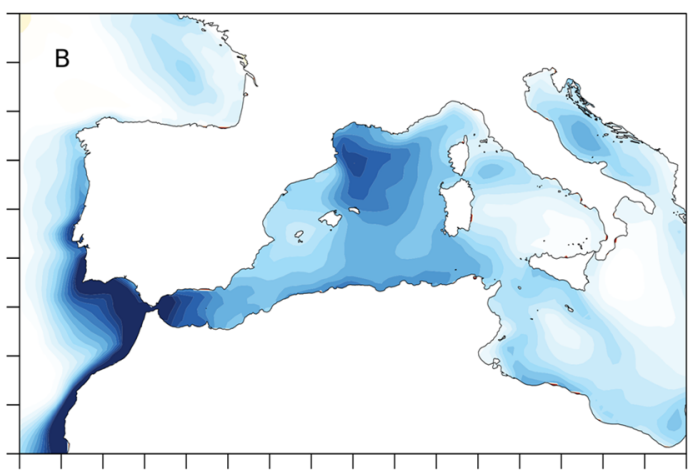

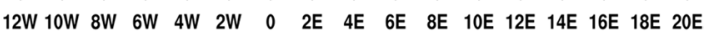
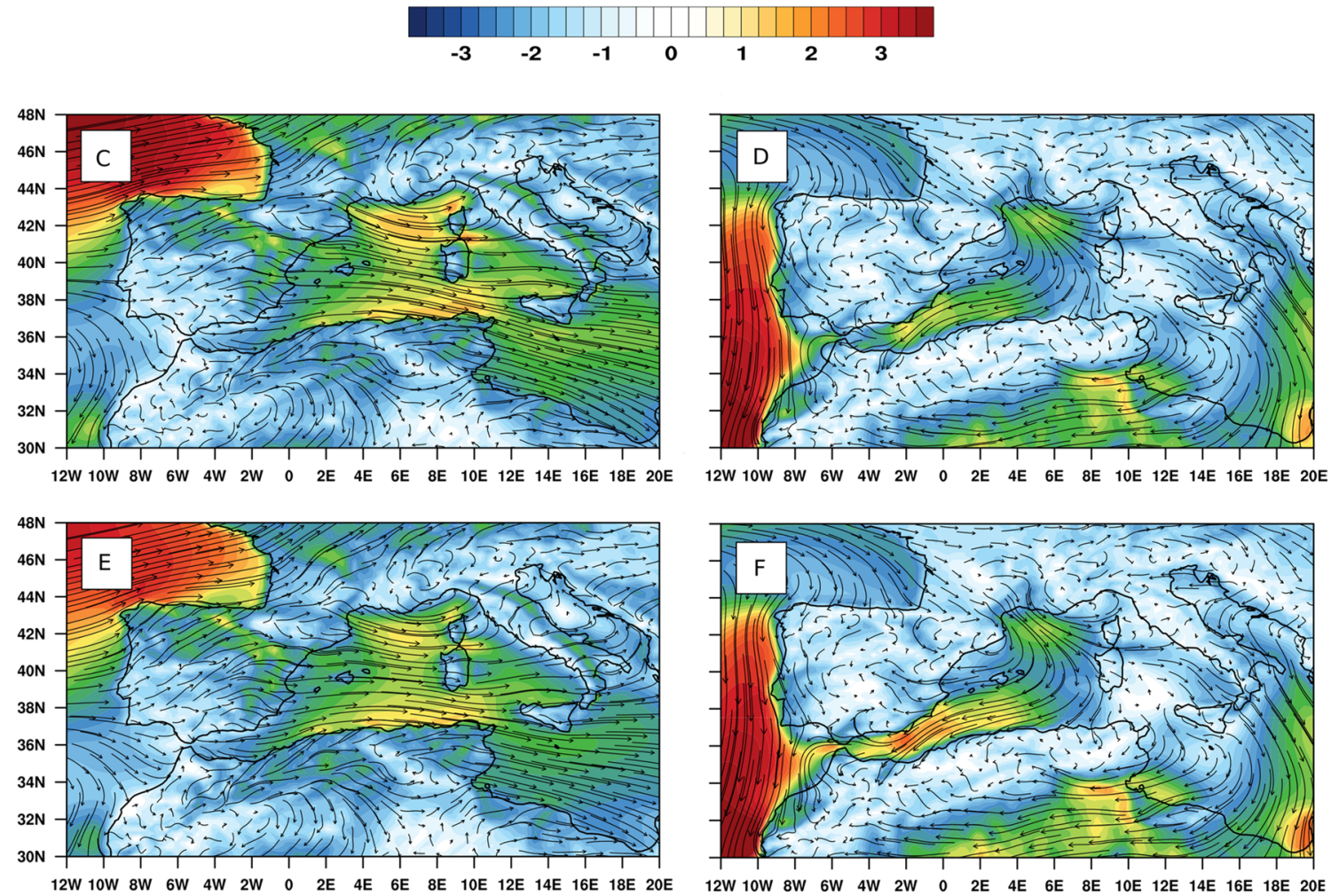

0.511 .5222 .533 .544 .555 .566 .57

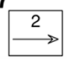

Fig. 14 Panels a-b: Winter and summer averages of the differences between the sea-surface temperature $\left({ }^{\circ} \mathrm{C}\right)$ from ROM and MPI-ESM. Panels c-f: Winter and summer averages of $10-\mathrm{m}$ wind speed direction (arrows) and module (m/s; colors) computed for ROM (c, d) and

better this upwelling of cold water along the western coast of the IP in summer (see Fig. 12f). Also, the along-shore wind in ROM decreases rapidly towards the coast, giving a strong wind-stress curl, which causes enhanced upwelling over a narrow coastal strip (e.g., de la Vara et al. 2020). In addition, the active air-sea coupling leads to a better heat exchange and thus to a larger influence of the ocean surface
MPI-ESM (e, f). All calculations are done for the 2070-2099 time period, assuming the RCP8.5 scenario. Winter plots are presented in the left column and the summer ones in the right column

temperature onto the air temperature. In turn, the cooling of the SST, may have an impact on T2M via winds (Fig. 13b, d, f). The wind-SST feedback plays an important role in these effects. The SST is decreased by the mechanical action of the wind, which causes more stirring. In turn, the SST affects the T2M through the modulation of the heat fluxes by the wind field by the thermal and current feedbacks (see for 
instance Renault et al. 2019 for a recent overview). On the Mediterranean Sea, we observe that ROM reproduces colder SSTs than MPI-ESM especially in summer (Fig. 14). This may affect T2M, which is lower in ROM (Fig. 13b, d, f). The colder T2M over the Mediterranean in ROM would reduce T2M over the IP (relative to REMO) due to the development of coastal winds that blow from the Mediterranean Sea towards the IP due to differential summer air-sea warming (Fig. 14d, f).

\subsection{Causal mechanisms for precipitation changes observed in the Iberian Peninsula}

As seen in previous sections, in both coupled and uncoupled simulations, winter precipitation increases over the Atlantic flank of the IP, while the eastern coast of the IP becomes drier by the end of the twenty-first century. However, on the one hand, the precipitation increase to the west of the IP in ROM is smaller than in REMO. On the other hand, rainfall decreases found in both models are of a lesser extent with ROM. This is, projected precipitation changes in the coupled simulation are of smaller magnitude than in the stand-alone REMO simulation. In Fig. 15a and b, we depict the precipitation over the North Atlantic for ROM and REMO. In general, precipitation is larger along the warm Gulf Stream and North Atlantic currents due to the enhanced latent heat loss over the SST gradients along these paths (see Cabos et al. 2020 for details). Precipitation is maximum over the Gulf Stream and the beginning of the North Atlantic Current, with values close to $10 \mathrm{~mm} /$ day and decreases gradually closer to the western coast of Europe. North Atlantic winter precipitation in ROM is smaller than in REMO, which is related to the generally lower SST in the coupled run, which may reduce the atmospheric instability (Pastor et al. 2001; Lebeaupin et al. 2006; Meroni et al. 2018b; see also Fig. 5S of the Supplementary Material). An important role is played by the trajectory of the North Atlantic Current which, in ROM, from $30^{\circ} \mathrm{W}$, is shifted to the north and to the west, further reducing the available precipitable water for the large-scale precipitation on the western side of the IP.

In summer, although a generalized decrease in precipitation occurs, especially to the north and to the east of the IP, conditions are less dry with REMO than with ROM (see Table 1). The fact that conditions are drier with ROM than with REMO may be related to the lower SST with ROM relative to MPI-ESM (Fig. 14b). Both in the Western Mediterranean Sea and the Atlantic waters adjacent to the IP the SST is lower in ROM. Although not shown for brevity, our results show that this reduces the water vapor over the Peninsula and thus precipitation in ROM (see also Cabos et al. 2020).

Our results suggest that a better resolved topography (elevation, size and orientation of the mountains) is crucial for the provision of precipitation projections in the IP mountainous regions. To illustrate this point, following Torma and Giorgi (2020), we represent in Fig. 6S the delta changes for $850 \mathrm{hPa}$ winds and precipitation along with the model topography for the driving GCM and the uncoupled and the coupled regional models. This figure clearly shows the way topography impacts the simulated climate change signal, and that the impact of the topography is seasonal dependent. In winter, when most of the precipitation changes are related to the large-scale component of the precipitation, they are modulated by the topographic shadowing effect (Torma and Giorgi, 2020). In summer, thermodynamic mechanisms (associated with high elevation convection; Giorgi et al. 2016) become important. It should be noted that there is a complementary mechanism of topography modulation that is not explored here: atmospheric aerosol loading also exerts a control of the orographic rainfall enhancement (Napoli et al. 2019).

The coupling further modulates this effect, as the ocean-atmospheric feedback changes the large-scale winds and the latent heat and, therefore, the amount of humidity transported by the wind inland (compare central and right panels in Fig. 6S). It should be noted that in this mechanism the role of the driving GCM is very relevant, as it largely controls the large-scale winds through the boundary conditions (Torma and Giorgi 2020). Over the ocean, the thermal and current feedbacks (Renault et al. 2019) seem to play an important role in determining the impact of the coupling on precipitation. With the resolution of the oceanic and atmospheric components of ROM in the North Atlantic and Mediterranean regions, they play a crucial role in the air-sea coupling, providing important mechanisms through which the SST and oceanic currents impact the atmospheric boundary layer dynamics. In particular, through the vertical mixing of horizontal momentum, horizontal gradients of SST impact the spatial structure of the surface wind convergence, which, in turn, influence the precipitation over the sea (Meroni et al. 2018a). Also, episodes of strong winds can entrain deep and cold water in the oceanic mixed layer, generating surface cooling. In the case of a shallow mixed layer and strongly stratified water column, the decrease in SST can significantly reduce the air column instability and, thus, the total amount of precipitation (Meroni et al. 2018b). As stressed above, the important role played by the large-scale winds for the climate signal highlights the importance of the forcing GCM (Torma and Giorgi 2020). The control of the forcing GCM over the regional model climate can also be seen in the oceanic turbulent heat fluxes: the interannual evolution of these fluxes in the coupled and uncoupled regional models are largely similar to the fluxes of the global model. However, the relationship between the latent heat fluxes simulated by the regional and global models has a strong 
DJF
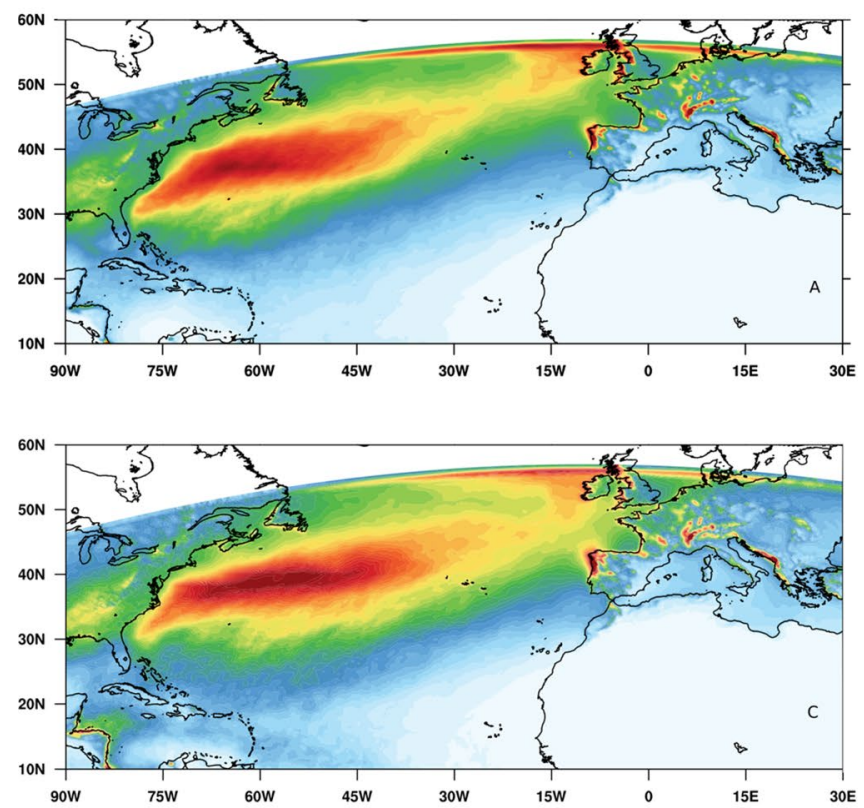

॥A
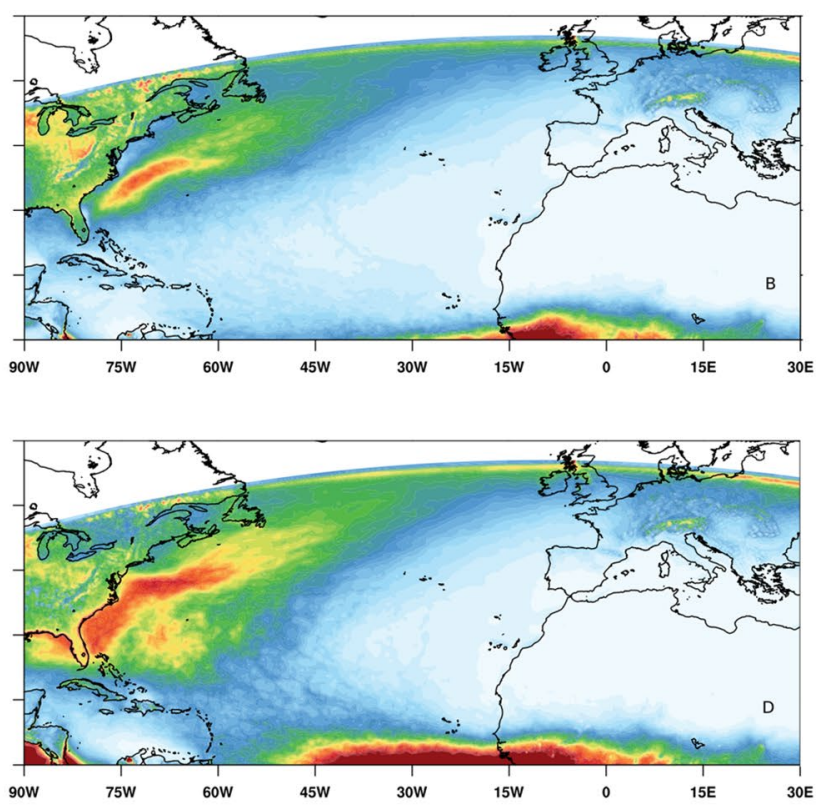

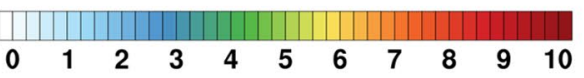

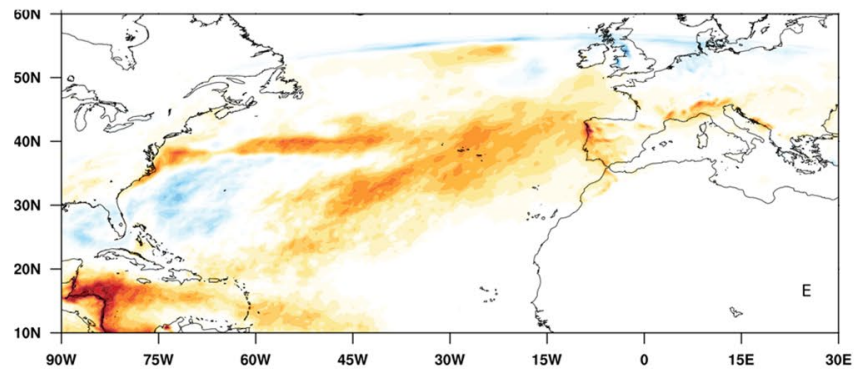

$-3-2.5-2-1.5-1-0.5 \quad 0 \quad 0.5 \quad 1 \quad 1.5222 .53$

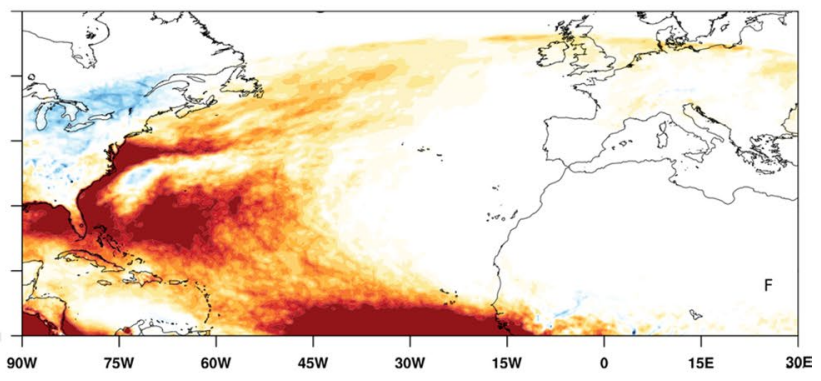

twenty-first century (i.e., a minus $\mathbf{c} ; \mathbf{b}$ minus $\mathbf{d})$. Positive values indicate that ROM precipitation is higher than in REMO and negative values the opposite. Winter plots are presented in the left column and the summer ones in the right column

which interact with a spatially-variable and complex topography. To this end, we use the regionally atmosphere-ocean coupled model ROM and its stand-alone atmospheric component REMO. We pay particular attention to the RCP8.5 scenario, as it provides a more significant climate change signal. An effort is made to understand the mechanisms that cause the differences between the climate of the reference future (2070-2099) and present time (1976-2005) periods. Additionally, we explore the climate change signal in ROM when the stabilization scenario RCP4.5 is considered. The differences between the climate change signal produced by the dynamical downscaling with ROM and the climate 
change signal produced by MPI-ESM are also examined. The most relevant findings from this study are summarized as follows.

\subsection{RCP8.5 scenario}

- The coupled simulation projects an increase in T2M, TMAX and TMIN in winter and summer. In winter, the 2-m air temperature rise is more subtle than in summer, and increases to a larger extent in highly-elevated mountain chains. In summer, temperature rises more sharply, especially in the central and southern portions of the IP.

- In the coupled simulation, winter precipitation decreases along the northern and southern flanks of the IP, with an increase to the NW of the peninsula, along the Galician and Portuguese coasts. In summer, however, drier conditions are found all over the peninsula, especially to the north.

- Differences in delta (future minus present) T2M, TMAX and TMIN from the coupled and uncoupled runs show that, in general, the $2-\mathrm{m}$ air temperature increase is stronger with the uncoupled than in the coupled model i.e., REMO projects a larger increase than ROM. Differences are more pronounced in the near-shore areas and especially in the summer season. This highlights the importance of air-sea interactions in this season.

- The coupled and uncoupled simulations agree on the spatial patterns of winter precipitation changes: an increase to the NW of the IP and a decrease to the north and to the $\mathrm{SE}$ of the peninsula. In summer, the two also agree on a general precipitation decrease which is more marked to the north of the IP. However, in both seasons, the uncoupled run gives changes of a greater magnitude than the coupled one.

- The lower T2M increase with the coupled model can be explained by differences in the North Atlantic and Mediterranean circulation. In winter, the SST in the North Atlantic is generally smaller in the coupled run. Also, the North Atlantic Current extends less to the east than in MPI-ESM (used to force the uncoupled simulation) and cold water from high-latitudes approaches the IP. The colder SST results in a colder T2M, which transports less heat towards the IP via the eastward branch of the Azores Anticyclone. In summer, the smaller T2M over the IP with the coupled model, especially to the NW of the IP, can be explained by the reinforcement of alongshore, northerly winds which promote upwelling in the coupled simulation. Also, the lower Mediterranean SST in the coupled run than in MPI-ESM drives a lower T2M over the IP via winds.

- The fact that in winter precipitation increases to a larger extent in the future with the uncoupled run than with the coupled one to the NW of the IP relates to changes in the
North Atlantic ocean circulation. These changes promote an enhanced latent heat flux which increases the water vapor content which is subsequently transported towards the IP through the descending branch of the anticyclone. In summer, whilst precipitation decreases more in the uncoupled than in the coupled simulation, precipitation is smaller in ROM. This is caused by a lower SST, which reduces the vapor content and thus precipitation.

\subsection{RCP4.5 scenario}

- In general, changes in T2M and precipitation under the RCP8.5 and RCP4.5 are qualitatively similar in the two coupled simulations with ROM. However, changes computed for the RCP4.5 scenario are of smaller magnitude. Different spatial patterns of changes are only found in winter precipitation over the NW of the IP. These differences are due to a lower North Atlantic SST, which reduces the latent heat flux and thus evaporation. This, in turn, drives a decreased precipitation in the North Atlantic and therefore the arrival of fronts to the IP.

\subsection{MPI-ESM}

- For the RCP8.5 scenario, ROM and MPI-ESM show a different climate change signal. Whilst the evolution of both signals is qualitatively similar, differences in resolution and model formulation lead to quantitative discrepancies. In the regional model, topography modulates the precipitation, with the coupling playing a further role. Over the ocean, the thermal and current feedbacks, active in ROM, seem to play an important role in determining the impact of the coupling on precipitation. This underlines the capability of the coupled simulation to simulate a different signal from that of the driving GCM.

Supplementary Information The online version contains supplementary material available at https://doi.org/10.1007/s00382-021-05812-x.

Acknowledgements A. de la Vara and William Cabos have been funded by the Spanish Ministry of Science, Innovation and Universities, the Spanish State Research Agency and the European Regional Development Fund, through Grant CGL2017-89583-R. William Cabos has also been supported by Salvador Madariaga grant (Spanish Ministry of Science Innovation and Universities). Dmitry Sein was supported in the framework of the state assignment of the Ministry of Science and Higher Education of Russia (theme No. 0128-2021-0014). Simulations were done on the German Climate Computing Center (DKRZ).

Funding Open Access funding enabled and organized by Projekt DEAL.

Open Access This article is licensed under a Creative Commons Attribution 4.0 International License, which permits use, sharing, adaptation, distribution and reproduction in any medium or format, as long 
as you give appropriate credit to the original author(s) and the source, provide a link to the Creative Commons licence, and indicate if changes were made. The images or other third party material in this article are included in the article's Creative Commons licence, unless indicated otherwise in a credit line to the material. If material is not included in the article's Creative Commons licence and your intended use is not permitted by statutory regulation or exceeds the permitted use, you will need to obtain permission directly from the copyright holder. To view a copy of this licence, visit http://creativecommons.org/licenses/by/4.0/.

\section{References}

Akhtar N, Brauch J, Ahrens B (2018) Climate modeling over the Mediterranean Sea: impact of resolution and ocean coupling. Clim Dyn 51(3):933-948

Bakun A, Nelson CS (1991) The seasonal cycle of wind-stress curl in subtropical eastern boundary current regions. J Phys Oceanogr 21(12):1815-1834. https://doi.org/10.1175/1520-0485(1991) 021\%3c1815:TSCOWS\%3e2.0.CO;2

Bartók B, Wild M, Folini D, Lüthi D, Kotlarski S, Schär C, Vautard R, Jerez S, Imecs Z (2017) Projected changes in surface solar radiation in CMIP5 global climate models and in EURO-CORDEX regional climate models for Europe. Clim Dyn 49:26652683. https://doi.org/10.1007/s00382-016-3471-2

Bougeault P (1983) A non-reflective upper boundary condition for limited-height hydrostatic models. Mon Weather Rev 111(3):420-429. https://doi.org/10.1175/1520-0493(1983)111\% 3c0420:ANRUBC\%3e2.0.CO;2

Buckley MW, Marshall J (2016) Observations, inferences, and mechanisms of Atlantic Meridional overturning circulation variability: a review. Rev Geophys 54:5-63. https://doi.org/10.1002/ 2015RG000493

Cabos W, Sein DV, Pinto JG, Fink AH, Koldunov NV et al (2017) The South Atlantic Anticyclone as a key player for the representation of the tropical Atlantic climate in coupled climate models. Clim Dyn 48(11-12):4051-4069. https://doi.org/10. 1007/s00382-016-3319-9

Cabos W, Sein DV, Durán-Quesada A, Liguori G, Koldunov NV, Martínez-López B, Alvarez F, Sieck K, Limareva N, Pinto JG (2018) Dynamical downscaling of historical climate over CORDEX Central America domain with a regionally coupled atmosphere-ocean model. Clim Dyn. https://doi.org/10.1007/ s00382-018-4381-2

Cabos W, de la Vara A, Álvarez-García FJ, Sánchez E, Sieck K, PérezSanz JI, LImaerva N, Sein DV (2020) Impact of ocean-atmosphere coupling on regional climate: the Iberian Peninsula case. Clim Dyn 54:4441-4467. https://doi.org/10.1007/s00382-020-05238-x

Cardoso RM, Soares PMM, Lima DCA, Miranda PMA (2019) Mean and extreme temperatures in a warming climate: EURO CORDEX and WRF regional climate high-resolution projections for Portugal. Clim Dyn 52:129. https://doi.org/10.1007/s00382-018-4124-4

Collins M, Minobe S, Barreiro M, Bordoni S, Kaspi Y, KuwanoYoshida A, Keenlyside N, Manzini E, O'Reilly CH, Sutton R et al (2018) Challenges and opportunities for improved understanding of regional climate dynamics. Nat Clim Change 8:101

Darmaraki S, Somot S, Sevault F, Nabat P, Narvaez WDC, Cavicchia L, Djurdjevic V, Li L, Sannino G, Sein DV (2019) Future evolution of marine heat waves in the Mediterranean Sea. Clim Dyn 53:1371-1392. https://doi.org/10.1007/s00382-019-04661-z

Davies HC (1976) A lateral boundary formulation for multi-level prediction models. Quart J Roy Meteor Soc 102:405-418

de la Vara A, Cabos W, Sein DV et al (2020) On the impact of atmospheric vs oceanic resolutions on the representation of the sea surface temperature in the South Eastern Tropical Atlantic. Clim Dyn 54:4733-4757. https://doi.org/10.1007/s00382-020-05256-9

Déqué M, Jones RG, Wild M, Giorgi F, Christensen JH, Hassell DC et al (2005) Global high resolution versus Limited Area Model climate change projections over Europe: quantifying confidence level from PRUDENCE results. Clim Dyn 25(6):653-670. https://doi.org/10.1007/s00382-005-0052-1

Déqué M, Somot S, Sanchez-Gomez E, Goodess CM, Jacob D, Lenderink G, Christensen OB (2012) The spread amongst ENSEMBLES regional scenarios: regional climate models, driving general circulation models and interannual variability. Clim Dyn 38(5-6):951-964

Di Sante F, Coppola E, Farneti R et al (2019) Indian Summer Monsoon as simulated by the regional earth system model RegCMES: the role of local air-sea interaction. Clim Dyn 53:759. https://doi.org/10.1007/s00382-019-04612-8

Dúran L, Sánchez E, Yagüe C (2013) Climatology of precipitation over the Iberian Central System mountain range. Int J Climatol 33(9):2260-2273. https://doi.org/10.1002/joc.3602

Font-Tullot I (2000) Climatología de España y Portugal, vol 76. Universidad de Salamanca

Gao X, Pal JS, Giorgi F (2006) Projected changes in mean and extreme precipitation over the Mediterranean region from a high resolution double nested RCM simulation. Geophys Res Lett 33:L03706. https://doi.org/10.1029/2005GL024954

Garrido JL, González-Rouco JF, Vivanco MG, Navarro J (2020) Regional surface temperature simulations over the Iberian Peninsula: evaluation and climate projections. Clim Dyn 55:34453468. https://doi.org/10.1007/s00382-020-05456-3

Giorgetta MA, Jungclaus J, Reick CH, Legutke S, Bader J, Böttinger M, Brovkin V et al (2013) Climate and carbon cycle changes from 1850 to 2100 in MPI-ESM simulations for the Coupled Model Intercomparison Project phase 5. J Adv Model Earth Sy 5:572-597. https://doi.org/10.1002/jame.20038

Giorgi F (2006) Climate change hot-spots. Geophys Res Lett. https:// doi.org/10.1029/2006GL025734

Giorgi F, Lionello P (2008) Climate change projections for the Mediterranean region. Glob Planet Change 63(2-3):90-104. https:// doi.org/10.1016/j.gloplacha.2007.09.005

Giorgi F, Marinucci MR, Visconti G (1992) A 2XCO2 climate change scenario over Europe generated using a limited area model nested in a general circulation model 2. Clim Change Scenario J Geophys Res-Atmos 97(D9):10011-10028. https:// doi.org/10.1029/92JD00614

Giorgi F, Hurrell JW, Marinucci MR, Beniston M (1997) Elevation dependency of the surface climate change signal: a model study. J Clim 10(2):288-296. https://doi.org/10.1175/15200442(1997)010\%3c0288:EDOTSC\%3e2.0.CO;2

Giorgi F, Torma C, Coppola E, Ban N, Schar C, Somot S (2016) Enhanced summer convective rainfall at Alpine high elevations in response to climate warming. Nat Geosc 9:584-590. https:// doi.org/10.1007/s00382-020-05456-3

Hagemann S, Dümenil Gates L (2001) Validation of the hydrological cycle of ECMWF and NCEP reanalyses using the MPI hydrological discharge model. J Geophys Res 106:1503-1510

Herrera S, Soares PMM, Cardoso RM, Gutierrez JM (2020) Evaluation of the EURO-CORDEX regional climate models over the Iberian Peninsula: observational uncertainty analysis. J Geophys Res-Atmos 125:e2020JD032880. https://doi.org/10.1029/2020J D032880

Jacob D (2001) A note to the simulation of the annual and interannual variability of the water budget over the Baltic Sea drainage basin. Meteorol Atmos Phys 77(1-4):61-73. https://doi.org/10. 1007/s007030170017 
Jacob D, Podzun R (1997) Sensitivity studies with the regional climate model REMO. Meteorol Atmos Phys 63(1-2):119-129. https://doi.org/10.1007/BF01025368

Jacob D et al (2014) EURO-CORDEX: new high resolution climate change projections for European impact research. Reg Environ Change 14(2):563-578. https://doi.org/10.1007/ s10113-013-0499-2

Jiménez-Guerrero P, Montávez JP, Domínguez M, Romera R, Fita L, Fernández J et al (2013) Mean fields and interannual variability in RCM simulations over Spain: the ESCENA project. Clim Res 57(3):201-220. https://doi.org/10.3354/cr01165

Jungclaus JH, Keenlyside N, Botzet M, Haak H, Luo JJ, Latif M et al (2006) Ocean circulation and tropical variability in the coupled model ECHAM5/MPI-OM. J Clim 19(16):3952-3972. https:// doi.org/10.1175/JCLI3827.1

Jungclaus JH, Fischer N, Haak H, Lohmann K, Marotzke J, Matei D, Mikolajewicz U, Notz D, vonStorch JS (2013) Characteristics of the ocean simulations in MPIOM, the ocean component of the MPI-Earth system model. J Adv Model Earth Syst 5:422-446. https://doi.org/10.1002/jame.20023

Keeley SPE, Sutton RT, Shaffrey LC (2012) The impact of North Atlantic sea surface temperature errors on the simulation of North Atlantic European region climate. Q J R Meteorol Soc 138(668):1774-1783. https://doi.org/10.1002/qj.1912

Kelemen FD, Primo C, Feldmann H, Ahrens B (2019) Added value of atmosphere-ocean coupling in a century-long regional climate simulation. Atmosphere 10:537. https://doi.org/10.3390/atmos 10090537

Klemp JB, Durran DR (1983) An upper boundary condition permitting internal gravity wave radiation in numerical mesoscale models. Mon Weather Rev 111(3):430-444. https://doi.org/10.1175/15200493(1983)111\%3c0430:AUBCPI\%3e2.0.CO;2

Kotlarski S et al (2014) Regional climate modeling on European scales: a joint standard evaluation of the EURO-CORDEX RCM ensemble. Geosci Model Dev 7:1297-1333. https://doi.org/10.5194/ gmd-7-1297-2014

Lebeaupin C, Ducrocq V, Giordani H (2006) Sensitivity of torrential rain events to the sea surface temperature based on high-resolution numerical forecasts. J Geophys Res 111:D12110. https://doi.org/ 10.1029/2005JD006541

Li H, Kanamitsu M, Hong SY, Yoshimura K, Cayan DR, Misra V, Sun L (2014) Projected climate change scenario over California by a regional ocean-atmosphere coupled model system. Clim Change 122:609-619. https://doi.org/10.1007/s10584-013-1025-8

Limareva NS, Cabos W, Izquierdo A, Sein DV (2017) The climate change of the caucasus as a result of the global warming. Современная Наука и Инновации 2:15-26

Lionello P, Malanotte-Rizzoli P, Boscolo R (eds) (2006) Mediterranean climate variability. Elsevier

Majewski D (1991) The Europa-Modell of the Deutscher Wetterdienst. ECMWF Seminar Numer Methods Atmosp Models 2:147-191

Marsland SJ, Haak H, Jungclaus JH, Latif M, Röske F (2003) The Max-Planck-Institute global ocean/sea ice model with orthogonal curvilinear coordinates. Oce Mod 5(2):91-127. https://doi.org/10. 1016/S1463-5003(02)00015-X

Martin-Vide J, Lopez-Bustins J (2006) The Western Mediterranean Oscillation and rainfall in the Iberian Peninsula. Int J Climatol 26:1455-1475. https://doi.org/10.1002/joc.1388

Martín-Vide J, Olcina J (2001) Climas y tiempos de España Madrid Alianza Editorial p. 258

Marzocchi A, Hirschi JJM, Holliday NP, Cunningham SA, Blaker AT, Coward AC (2015) The North Atlantic subpolar circulation in an eddy-resolving global ocean model. J Mar Syst 142:126-143. https://doi.org/10.1016/j.jmarsys.2014.10.007

Meroni AN, Parodi A, Pasquero C (2018a) Role of SST patterns on surface wind modulation of a heavy midlatitude precipitation event. J Geophys Res 123:9081-9096. https://doi.org/10.1029/ 2018JD028276

Meroni AN, Renault L, Parodi A, Pasquero C (2018b) Role of the oceanic vertical thermal structure in the modulation of heavy precipitations over the Ligurian Sea. Pure Appl Geophys 175:4111-4130. https://doi.org/10.1007/s00024-018-2002-y

Michaelis AC, Willison J, Lackmann GM, Robinson WA (2017) Changes in winter North Atlantic extratropical cyclones in highresolution regional pseudo-global warming simulations. J Climate 30:6905-6925. https://doi.org/10.1175/JCLI-D-16-0697.1

Minobe S, Kuwano-Yoshida A, Komori N, Xie SP, Small RJ (2008) Influence of the Gulf Stream on the troposphere. Nature 452(7184):206. https://doi.org/10.1038/nature06690

Napoli A, Crespi A, Ragone F, Maugeri M, Pasquero C (2019) Variability of orographic enhancement of precipitation in the Alpine region. Sci Rep 9:13352. https://doi.org/10.1038/ s41598-019-49974-5

Palazzi E, Mortarini L, Terzago S, von Hardenberg J (2019) Elevationdependent warming in global climate model simulations at high spatial resolution. Clim Dyn 52:2685-2702. https://doi.org/10. 1007/s00382-018-4287-z

Parras-Berrocal I, Vazquez R, Cabos W, Sein D, Mañanes R, PerezSanz J, Izquierdo A (2020) The climate change signal in the Mediterranean Sea in a regionally coupled ocean-atmosphere model. Ocean Sci. https://doi.org/10.5194/os-2019-42

Pastor F, Estrela MJ, Penarrocha D, Millán MM (2001) Torrential rains on the Spanish Mediterranean coast: modeling the effects of the sea surface temperature. J Appl Meteorol 40:1180-1195

Ramos AM, Cortesi N, Trigo RM (2014) Circulation weather types and spatial variability of daily precipitation in the Iberian Peninsula. Front Earth Sci 2:25. https://doi.org/10.3389/feart.2014.00025

Rangwala I, Miller JR (2012) Climate change in mountains: a review of elevation-dependent warming and its possible causes. Clim Change 114:527-547. https://doi.org/10.1007/s10584-012-0419-3

Renault L, Masson S, Oerder V, Jullien S, Colas F (2019) Disentangling the mesoscale ocean-atmosphere interactions. J Geophys Res. https://doi.org/10.1029/2018JC014628

Riahi K, Rao S, Krey V et al (2011) RCP 8.5-a scenario of comparatively high greenhouse gas emissions. Clim Change 109:33. https://doi.org/10.1007/s10584-011-0149-y

Rijo NA, Semedo A, Miranda PMA, Lima DCA, Cardoso RM, Soares PMM (2017) Spatial variability of the Iberian Peninsula coastal low-level jet. Int J Clim 38(4):1605-1622. https://doi.org/10.1002/ joc.5303

Rodríguez-Puebla C, Encinas AH, Nieto S, Garmendia J (1998) Spatial and temporal patterns of annual precipitation variability over the Iberian Peninsula. Int J Climatol 18(3):299-316

Rodríguez-Puebla C, Encinas AH, Sáenz JY (2001) Winter precipitation over the Iberian Peninsula and its relationship to circulation indices. Hydrol Earth Syst Sci 5(2):233-244

Roeckner E, Arpe K, Bengtsson L, Christoph M, Claussen M, Dümenil L, et al (1996) The atmospheric general circulation model ECHAM-4: model description and simulation of present-day climate

Roeckner E, Bäuml G, Bonaventura L, Brokopf R, Esch M, Giorgetta M, et al (2003) The atmospheric general circulation model ECHAM 5. PART I: Model description

Rotach MW, Marinucci MR, Wild M, Tschuck P, Ohmura A, Beniston M (1997) Nested regional simulation of climate change over the Alps for the scenario of a doubled greenhouse forcing. Theor Appl Climatol 57(3-4):209-227. https://doi.org/10.1007/BF00863614

Rummukainen M (2016) Added value in regional climate modeling. Wires Clim Change 7:145-159. https://doi.org/10.1002/wcc.378

Sein DV, Koldunov NV, Pinto JG, Cabos W (2014) Sensitivity of simulated regional Arctic climate to the choice of coupled model 
domain. Tellus A 66(1):23966. https://doi.org/10.3402/tellusa. v66.23966

Sein DV, Mikolajewicz U, Gröger M, Fast I, Cabos W, Pinto JG, Hagemann S, Semmler T, Izquierdo A, Jacob D (2015) Regionally coupled atmosphere-ocean- sea ice-marine biogeochemistry model ROM: 1. J Adv Model Earth Syst 7(1):268-304. https://doi.org/ 10.1002/2014MS000357

Sein DV, Koldunov NV, Danilov S, Sidorenko D, Wekerle C, Cabos $\mathrm{W}$ et al (2018) The relative influence of atmospheric and oceanic model resolution on the circulation of the North Atlantic Ocean in a coupled climate model. J Adv Model Earth Syst 10:2026-2041. https://doi.org/10.1029/2018MS001327

Sein D, Dvornikov A, Martyanov S, Cabos W, Ryabchenko V, Groeger M, Kumar P (2020b) Impact of the Indian Ocean temperaturephytoplankton feedback on simulated South Asia climate. Essoar. https://doi.org/10.1002/essoar.10503384.1

Sein DV, Gröger M, Cabos W, Alvarez-Garcia FJ, Hagemann S, Pinto JG et al (2020a) Regionally coupled atmosphere - ocean - marine biogeochemistry model ROM: 2. Studying the climate change signal in the North Atlantic and Europe. JAMES 12:e2019MS001646. https://doi.org/10.1029/2019MS001646

Semmler T, Jacob D (2004) Modeling extreme precipitation eventsa climate change simulation for Europe. Global Planet Change 44(1-4):119127. https://doi.org/10.1016/j.gloplacha.2004.06.008

Soares PMMM, Semedo A, Cardoso R, Chinita MJ, Ranjha R (2014) The Iberian Peninsula coastal low level jet. Tellus A 66:22377. https://doi.org/10.3402/tellusa.v66.22377

Somot S, Houpert L, Sevault F, Testor P, Bosse A, Taupier-Letage I, Bouin M-N, Waldman R, Cassou C, Sanchez-Gomez E, Durrieu de Madron X, Adloff F, Nabat P, Herrmann M (2018) Characterizing, modelling and understanding the climate variability of the deep water formation in the North-Western Mediterranean Sea. Clim Dyn 51:1179-1210. https://doi.org/10.1007/ s00382-016-3295-0
Sun X, Vizy EK, Cook KH (2019) Land-atmosphere-ocean interactions in the southeastern Atlantic: interannual variability. Clim Dyn 52:539. https://doi.org/10.1007/s00382-018-4155-x

Taylor KE, Stouffer RJ, Meehl GA (2012) An overview of CMIP5 and the experiment design. Bull Am Meteorol Soc 93:485-498. https://doi.org/10.1175/BAMS-D-11-00094.1

Torma C, Giorgi F (2020) On the evidence of orographical modulation of regional fine scale precipitation change signals: the Carpathians. Atmos Sci Lett 21:e967. https://doi.org/10.1002/asl.967

Ulbrich U, May W, Li L, Lionello P, Pinto JG, Somot S (2006) The Mediterranean climate change under global warming. In: Developments in earth and environmental sciences, vol 4. Elsevier, pp $399-415$

Valcke S, Caubel A, Declat D, Terray L (2003) OASIS3 ocean atmosphere sea ice soil user's guide. Prisim project report, 2

Van der Linden P, Mitchell J E (2009). ENSEMBLES: climate change and its impacts: summary of research and results from the ENSEMBLES project. Met Office Hadley Centre, FitzRoy Road, Exeter EX1 3PB, UK, 160

Willison J, Robinson WA, Lackmann GM (2015) North Atlantic storm-track sensitivity to warming increases with model resolution. J Clim 28(11):4513-4524. https://doi.org/10.1175/ JCLI-D-14-00715.1

Zorita E, Kharin V, Von Storch H (1992) The atmospheric circulation and sea surface temperature in the North Atlantic area in winter: their interaction and relevance for Iberian precipitation. J Clim 5(10):1097-1108. https://doi.org/10.1175/1520-0442(1992)005\% 3c1097:TACASS\%3e2.0.CO;2

Publisher's Note Springer Nature remains neutral with regard to jurisdictional claims in published maps and institutional affiliations. 